Website: http://jsci.utq.edu.iq Email: utjsci@utq.edu.iq تأثير المستخلص الكحولي للبر وبوليس ( صمغ النحل ) في التقليل من سميته الأكريلمايد في إناث الجرذان المختبرية

جميلة كاظم عبد الحسن العمري كليةالطب البيطري
وسام عبدان و ادي الخالدي*

حسين خضير عبيس الميالي * كلية التربية

جامعة القادسية

الخلاصة:

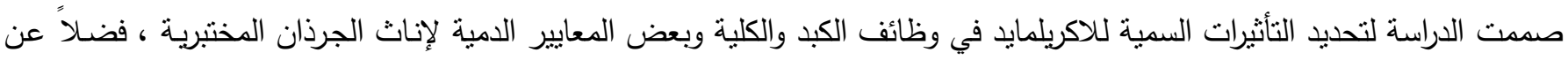

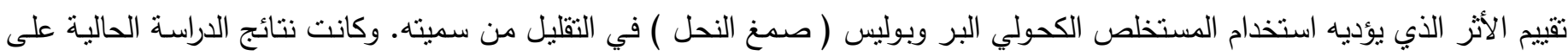
النحو الآتي: انخفاض معنوي (P<0.05) في وزن الجسم ومعدل الكسب ألوزني في المجموعة المعاملة بالأكريلمايد مقارنة مع مجموعة السيطرة. في

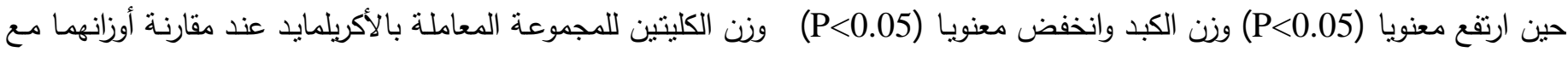

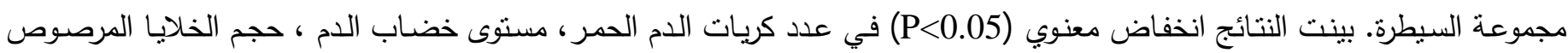
وعدد خلايا الدم البيض الكلي في المجموعة B المعاملة بالأكريلمايد بتركيز (150 ملغم / كغم) مقارنة مع مجموعة السيطرة.

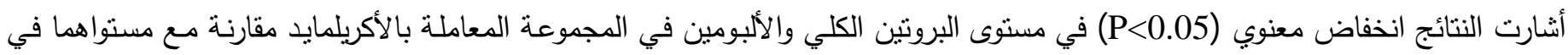
مجموعة السيطرة، قابله ارتفاع معنوي (P<0.05) في مستوى الكلوبيولين، الكرياتين و اليوريا في المجموعة الثانية (B) المعاملة بالأكريلمايد مقارنة مع مجموعة السيطرة.

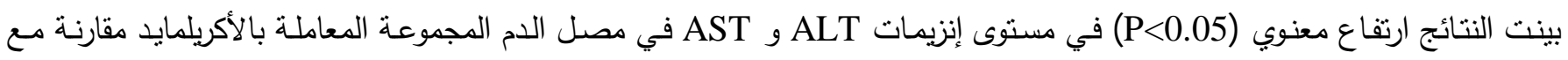
مستواهما في مجموعة السيطرة.أظهرت نتائج الفحص النسجي تغيرات مرضية منباينة تنتلت باحتقان الأوعية الدموية والنزف الدموي، في كل من الكبد والكليتين، إضافة إلى نحلل بطانة النبيبات الكلوية وتتخر الخلايا الكبدية.

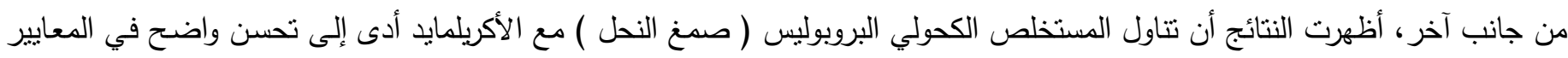

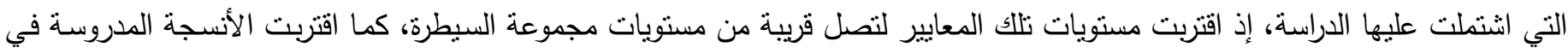

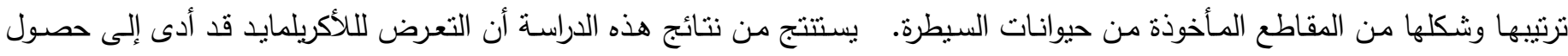

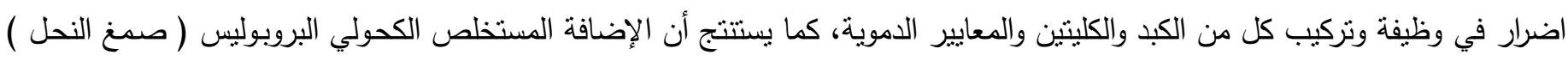
مع اللأكريلمايد قد ساهم في تقليل تأثيراته السمية. 
بالثمع ومن ثم يستخدم في الخلية لسد الثقوق ولحماية الخلية من

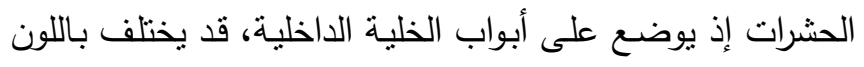

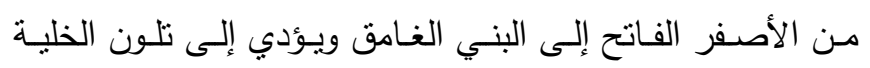

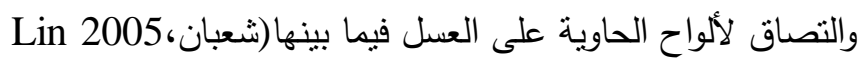
طي (et. al., 1999 ; طبيعي ضد الجراثيم والفايروسات ومقوي للجهاز المناعي ومضاد للسرطان(Lin et. al., 1999). يفيد في شفاء الجروح، علاج الحروق، الأكزيما ، الإصـابات الجلدية الفطريـة، علاج الروماتيزم

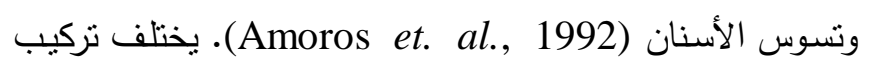

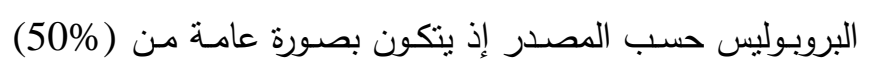
(10\%)، شيوت (30\%)، Vegetable baslsam resin

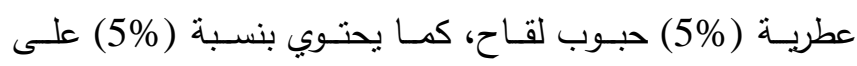

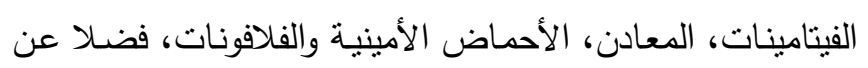
Caffeic acid esters (2-20 ، Hydroquinone (11\%) (Greenway et. Quercetinc $(0.1-0.7 \%) \cdots \%)$ . al., 1991)

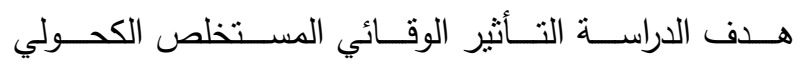

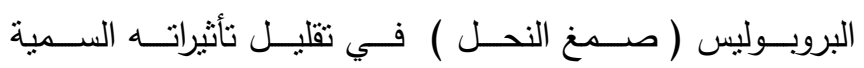
اللأكريلمايد في إناث الجرذان.

\section{المو اد وطر ائق العمل:}

\section{حيوانات التجرية :}

أجريت هذه الدراسة في البيت الحيواني التابع إلى كلية التربية -

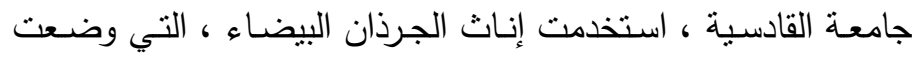
بأقفاص بلاستيكية مزودة بغطاء حديدي مشبك ، تم إيواء الحيوانات

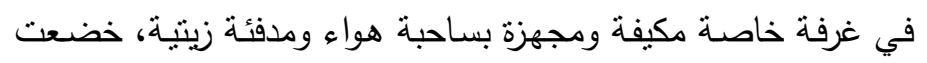
حيوانات التجربة إلى ظروف مختبريه مناسبة بدرجة حرارة (20 -25) م ومدة إضـاءة 12 سـاعة و 12 سـاعة ظـلام وقد زودت الحيوانـات

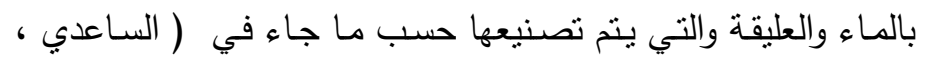

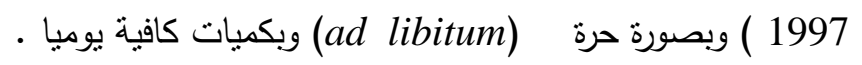

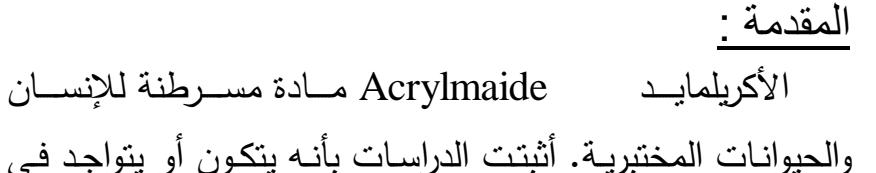

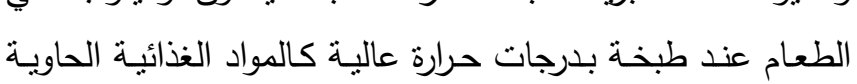

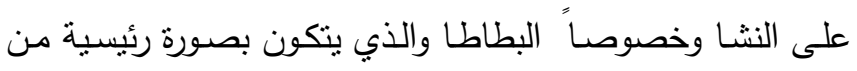

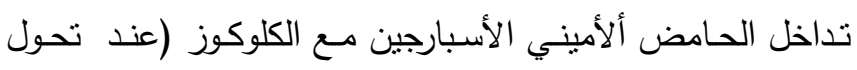

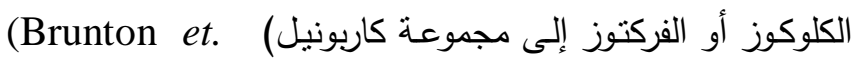
وكذلك يتواجد في تبخ al., 2005 ; Tareke et. al., 2002) السكائر ، وعند حرق السكائر عند التدخين (EC,2000) وعند ما

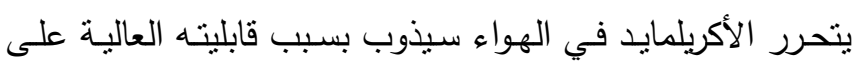

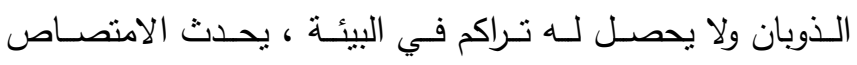

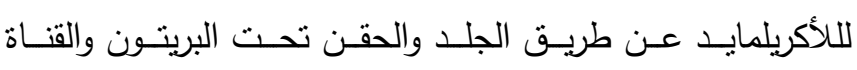

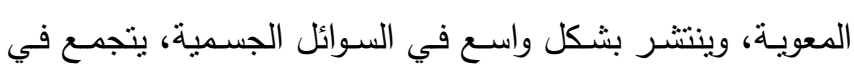

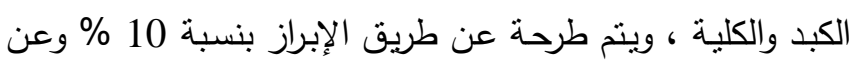
طريق اليوريا والصفراء(Barber, 2001) ينتقل إلى الدم بعد 24

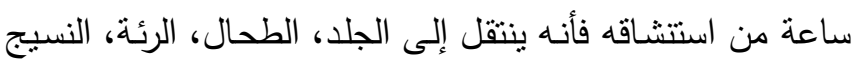

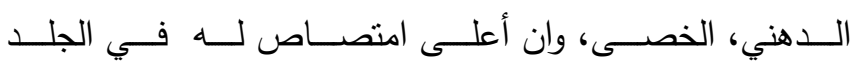
. (Sumner, 2001)

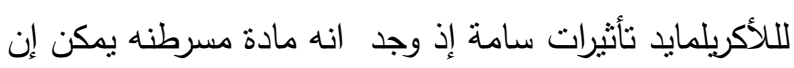

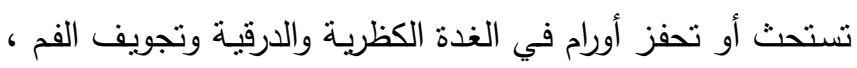
الخصية، الغدد الثديية والرحم(Pelucchi et. al., 2005) وكذلك أثنتت سميته الوراثيـة إذ يحدث تشوهات كروموسومية،

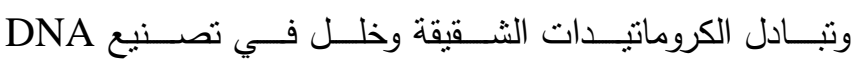
كما لـه تأثيرات سلبية في (Ghanayem et. al., 2005) خصوبة الذكور والإناث ، وتغيرات بالسلوك الجنسي، وانخفاض

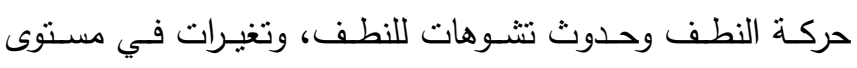

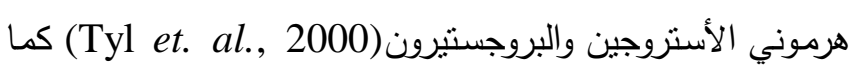
(Gold et. al., إن له نأثيرات سمية على الجهاز العصبئ ولبروجيروني .2004)

البروبولس Propolis (صمغ العسل) مـادة راتتجيـة تجمعها شغالات النحل من براعم بعض أنواع الأشجار ، إذ تقوم الثخالات

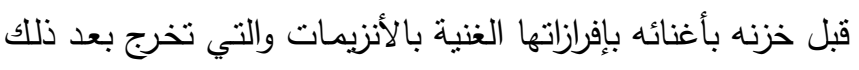


الفحوصات الدموية والكيموحيوية:

تـم تخـدير الحيوانـات بواسـطة الكلوروفـورم بعـد نهايـة مـــة

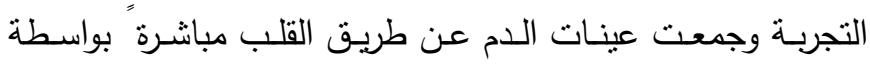

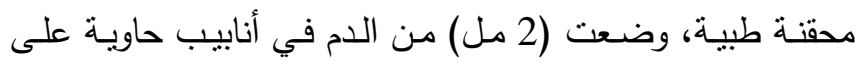

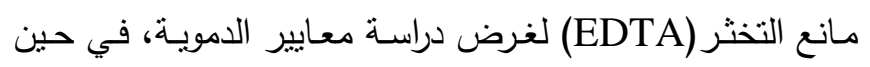
وضـع (3 مـل) مـن الـدم في أنابيـب زجاجيـة خاليـة مـن المـادة المانعة للتخثر ودورت بجهاز الطرد المركزي بسرعة 3000 دورة

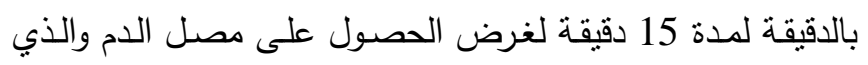
حفظ في أنابيب بلاسنيكية خاصة في درجة حرارة ( - 20 م) إلى دلى دأل

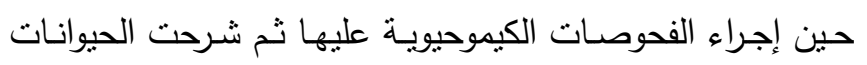
وتم استنصسال الكبد والكلية ووضعت في المحلول الفسلجي بعدها أخذت أوزانها ثم ثبتت بوضعها في الفورمالين (10\%) لتحضير

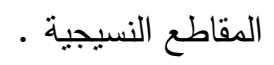
أولا : المعايير الدموية :

أ - حساب عدد كريات الدم الحمر : تم حساب عدد كريات

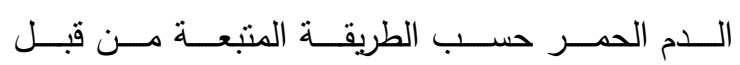

. (Chanarin,1989)

ب - حساب تركيز خضـاب الدم : تم استعمال جهاز مقياس الهيموكلوبين Hemoglobin Meter ومحلول درابكن تخفيف لتقدير نركيز الهيموكلوبين في عينة الدم (سود،

.) (1992

ت - حسـاب حجم الخلايـا المرصسوص: تم الحسـاب بواسطة طريقة Micro-haematocrite reader وكما جاء في

.(Sood, 1996 )

ث - العدد الكلي لخلايا الدم البيض: تم حساب العدد الكلي

لخلايا الدم البيض بحسب طريقة (Weir,1989) . ثانيا : الفحوصات الكيموحيوية :

أ - تقدير البـروتين الكلـي في المصـل :اســتخدمت طريقـة بايوريت Biuret Method لتقدير البروتين الكلي في مصل الدم (Tietz, 1982 ) . بائ
تحضير المستخلص الايثانولي للبرويولييس : مزج 50 غم من مسحوق مادة البروبولس مع 450 مل من الاينس

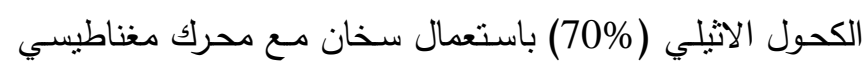

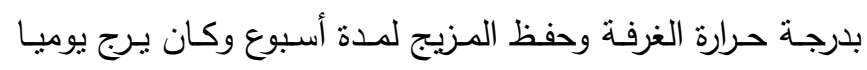

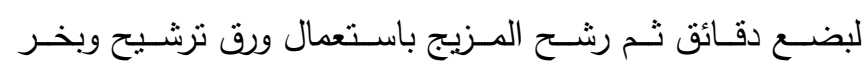

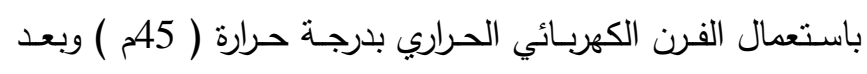

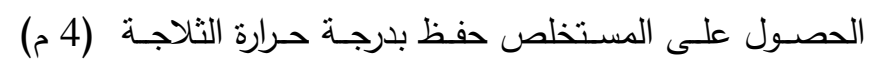
لحين الاستعمال ( Krell , 1996$)$ تصميم الدراسة: تم تقسـيم (18) أنثى ناضـجة جنسـياً عشـوائيا إلـى ثنلاتـة

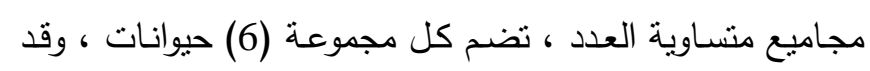
عوملت الحيوانات على النحو التالي : 1 - مجمعة السيطرة (A): أعطيت ماء الشراب الاعنيادي لمدة التجربة البالغة أربع أسابيع.

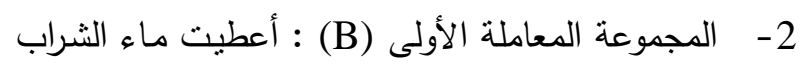

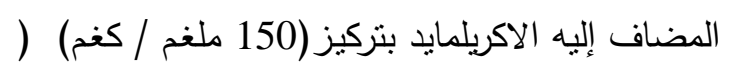

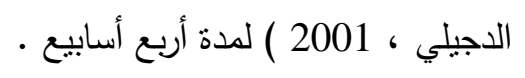

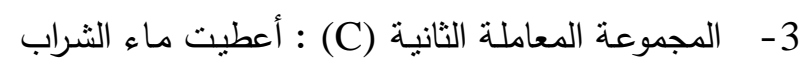
الاعتيادي المضاف إليه الاكريلمايد بتركيز (150 ملغن : اعند

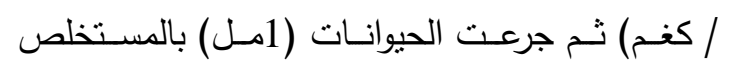

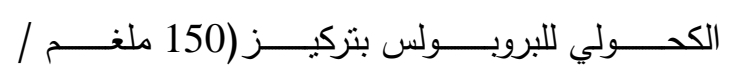

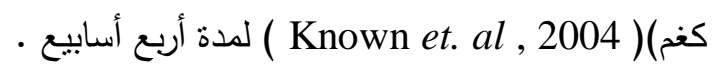
معايير الدراسة :

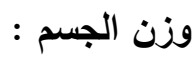
تم تسجيل وزن الجسم الكلي (غم ) لكل حيوان قبل وبعد انتهاء التجربة باستخدام ميزان حساس، وتم استخراج معدل الوزن

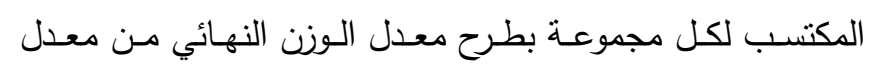
الوزن الابتدائي. وزن الأعضاء: بعد نهايـة التجربـة شـرحت الحيوانـات واستخرجت الأعضـاء

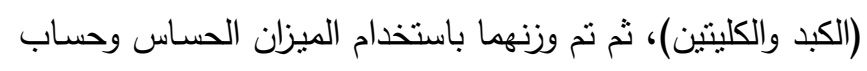

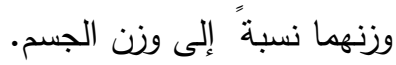


النتائج و المناقشتة:

التغيرات الوزنية

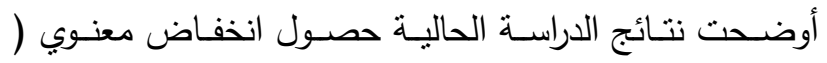

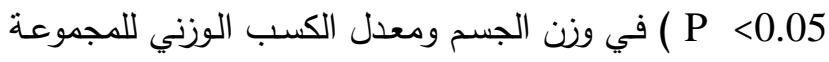

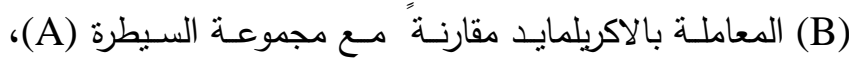
وجاءت النتيجة مطابقة مـ نتائج (Sharma et al, 2008) قد يعزى السبب إلى تأثثر الاكريلمايد السام على الجهاز العصبي فقد

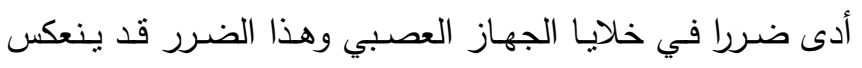

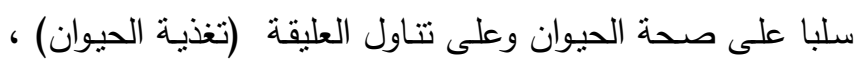

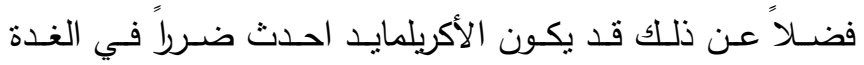
النخاميـة التي لها دور في السبطرة على الهورمونـات المحرضــة

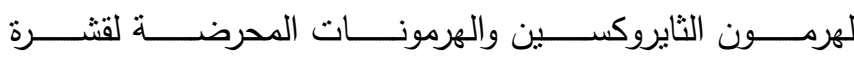
Adrenocortico trophic Stimulating (ACTH) الكظر Hormones .وفي المقابل بينت النتائج إن (Xiwen \& Jing, 1992 ) الحيوانـات التي تتاولت البروبولس مـع الاكريلمايد في المجموعـة ارتفع معدل وزن الجسم ومعدل الكسب الوزني مقارنـة مـع (C) المجموعة B المعاملة بالأكريلمايد لوحدة ، و اكتسبت وزنا مقاربا

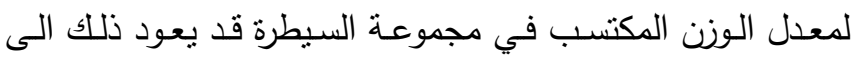

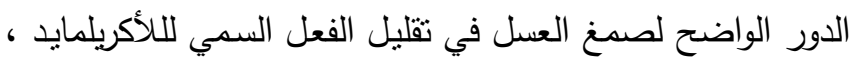
ولعل سبب ذللك يعود إلى فعل مكونات البروبولس والذي يتميز بالمحتوى العالي من المواد ذات القيمة الغذائية العالية التي من

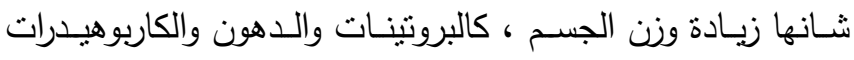
إضـافة إلىى الفيتامينـات والعناصـر المعدنيـة ، كمـا إن محتويـات

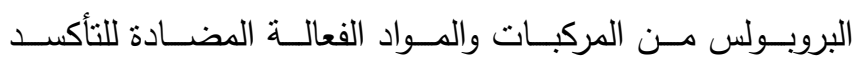
كالمركبات الفلافونويديـة وغيرهـا قد تكون سببا أساسيا في وقايـة الجسم من تراكم الجذور الحرة التي يزداد مستواها نتيجة للتأثنرات

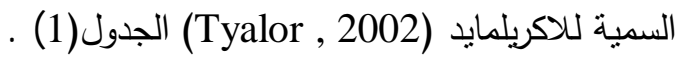
أوزان الأعضاء:

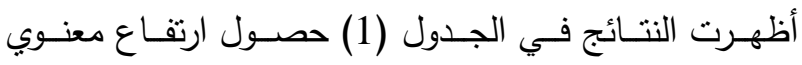

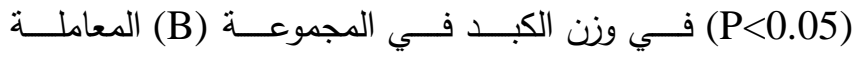
بالأكريلمايد مقارنة مـع مجموعة السيطرة(A) . وانخفاض معنوي
ب -تقدير الألبومين في المصل : تم تقدير الألبومين باستخدام

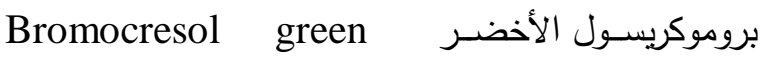
. Rod key , 1965 ( ) من قبل mod ت - تقدير مسـتوى الكلوبيـولين فـي مصـل الــدم: تـم تقدير مستوى الكلوبيـولين في مصـل الـدم بعمليـة حسـابية وفق مق مقئ

$$
\text { القانون الآتي: }
$$

تركيز الكلوبيولين (غم/100مل) = تركيز البروتين الكلي

$$
\text { (غم/100مل) - نركيز الألبومين (غم/100مل). }
$$

ث - ALT , AST تقدير فعالية الإنزيمات الناقلة للامين النين (Reitman اتبعت الطريقة اللونية للعالمين ( F Frankel , 1957) للامين وهما ALT A sportate Amino transferase AST Alanine Amino transferase دوليـة / لتر ) واسـتخدمت عدة التحاليـل المسـتخدمة مـن شركة Giesse الايطالية . ج - قياس مستوى اليوريـا في مصل الدم : تم تقدير مسنتوى اليوريا حسب طريقة Diacebyl manoxime والموصوفة

$$
\text { من قبل ( الخياط ، } 1992 \text { ) . }
$$

ح - قياس مستوى الكرياتين في مصل الدم : تم تقدير الكرياتين للام حسب طريقة (Jaffe) والموصوفة من قبل ( العمري

. ( 1986 ،

تحضير المقاطع النسجية :

تم تحضـير المقاطع النسـية للأعضـاء التي شملت عليها

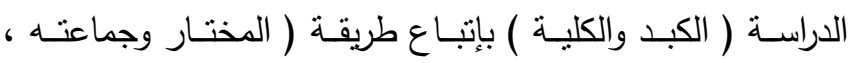
. ( 1982

التحليل الإحصائي : خصني خضعت النتائج للتحليل الإحصائي لمعرفة الفروقات المعنوية

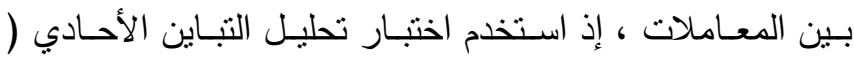
One way Analysis Variance (ANOVA الفروقات وذلك باستخدام اقل فرق - + 
فانه يؤدي اضطرابا في هرمون الارثروبيوتين المسؤول عن إنتاج

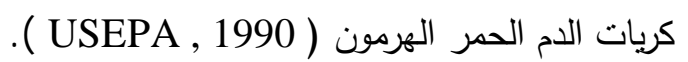

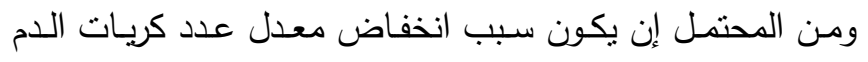
الحمر إلى حدوث خلل في تخليق هرمون الارثروبيوتين الهرمون

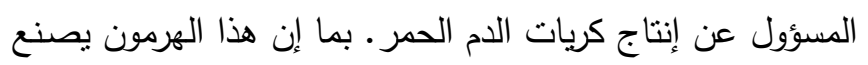
من قبل النبييات الكلوية ولطالما إن الاكريلمايد يسبب تلف لظهان لظهارة

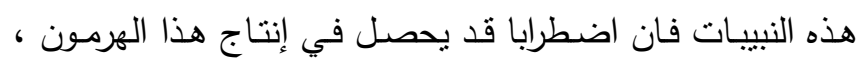

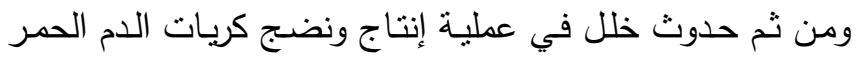

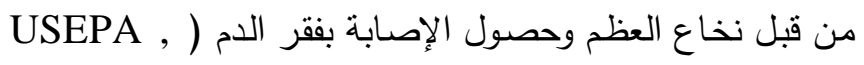

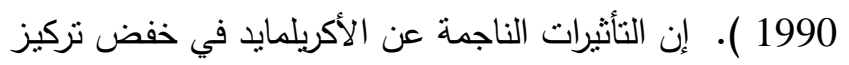
خضاب الدم الجدول (2) يعود إلى انخفاض عدد كريات الدم الدمان

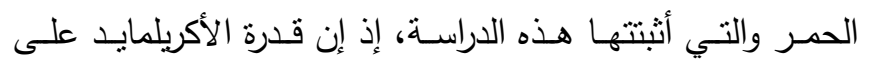

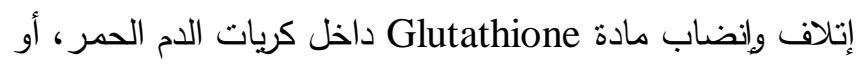

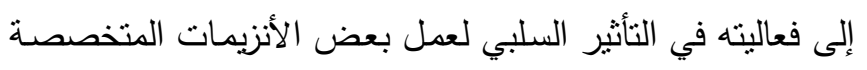

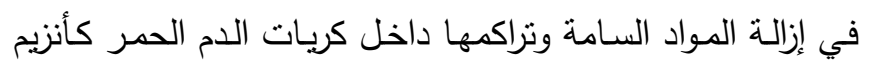
Glutathione peroxidase مما يؤدي إلى تقليل عمر كريه الفيه

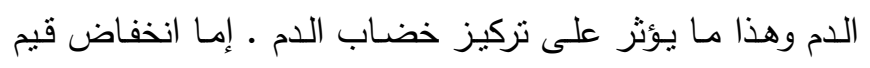
مكداس الدم يؤيد ماتم ملاحظته في نتائج من انخفاض فركاب في تركيز

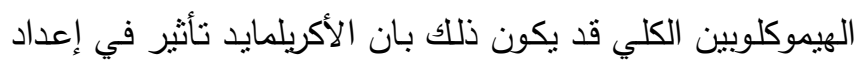

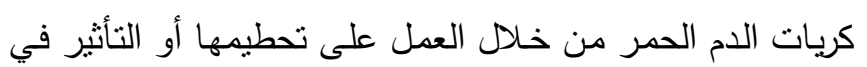

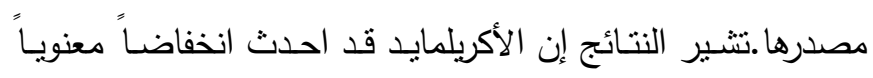

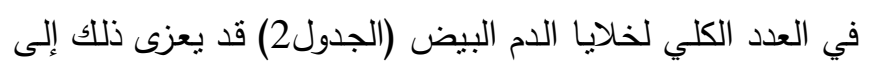

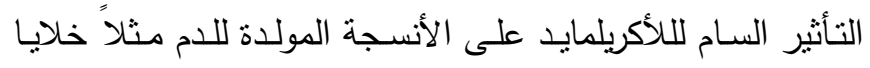

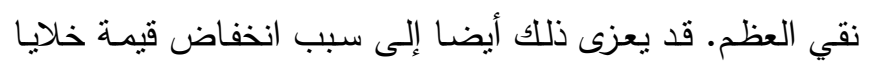

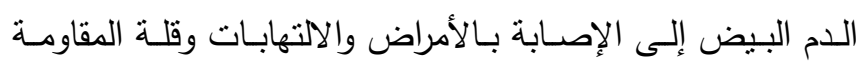

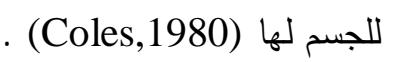

إن قيم تلك المعايير الدمية (RBC, Hb, PCV, WBC)

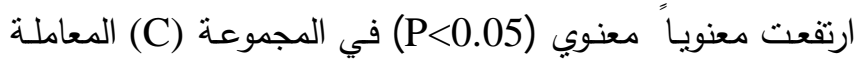
باللأكريلمايد + المستخلص الكحولي للبروبوليس (صمخ العسل)

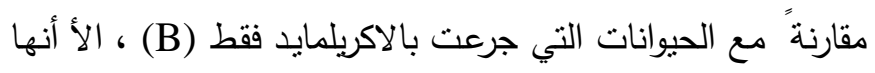

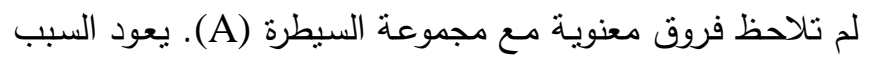

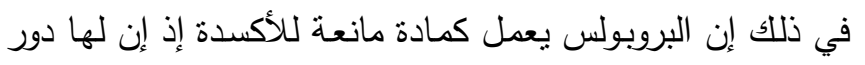

في وزن الكليتين للحيوانات المعاملة بالأكريلمايد في (P<0.05)

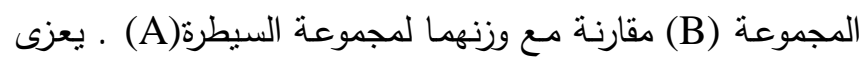

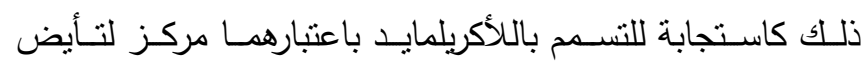

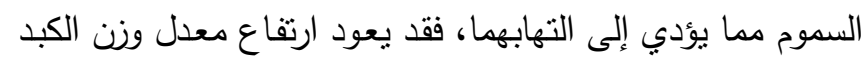

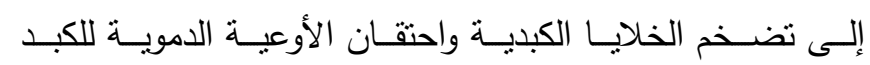

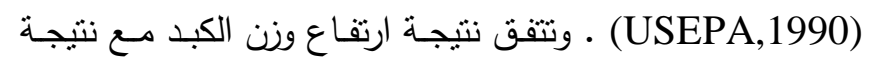
(Sharma et. al.., 2008)

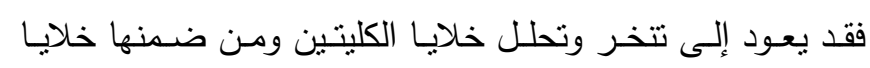
النبيبات الملتوية الدانية والقاصية واضمحلال الخلايا الأندوثيلية

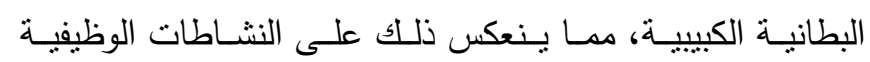

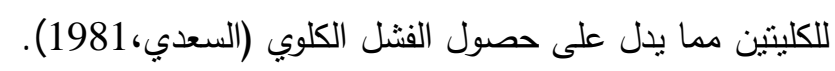

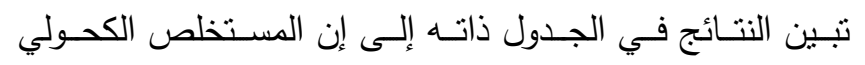
اللبروبوليس قد أدى إلى انخفاض وزن الكبد معنوياً (P<0.05)

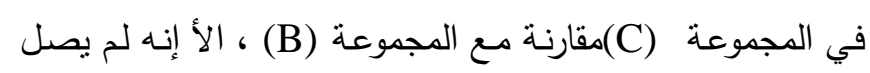

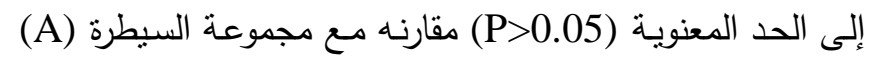

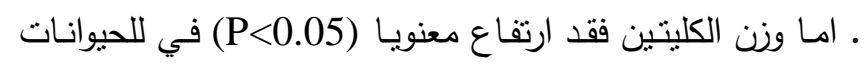

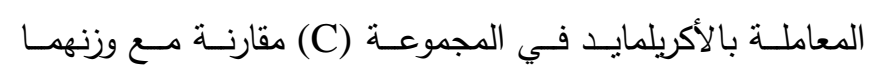

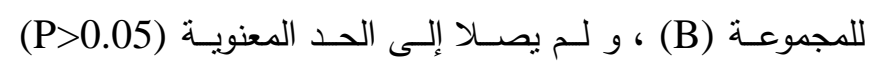

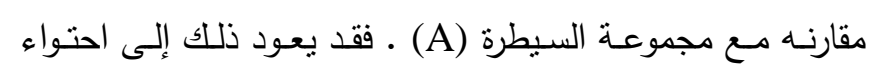

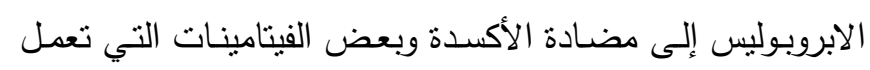

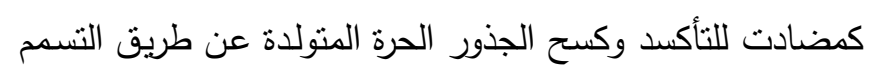

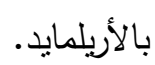

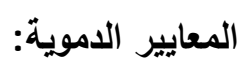
أنشـارت النتائج المبينــة في الجـدول (2) انخفاضــا معنويـا

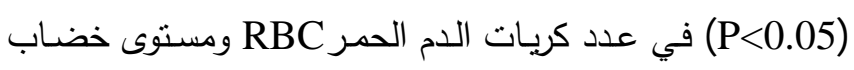

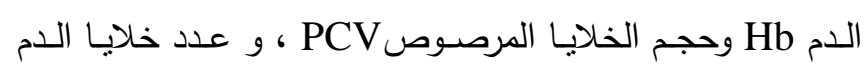

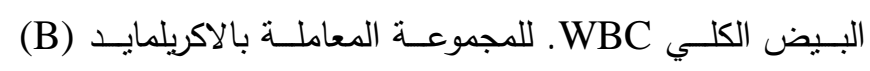

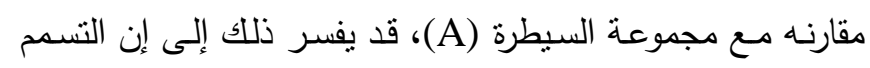

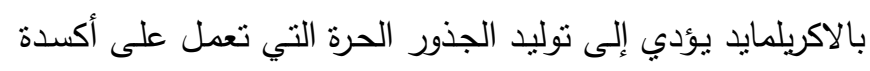

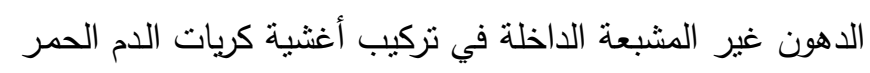

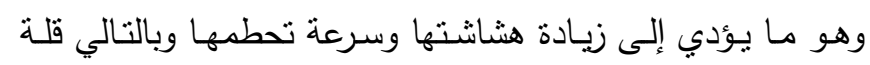

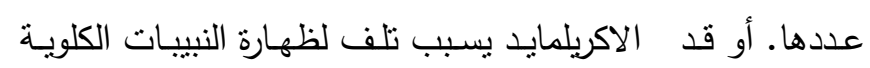


المصلي للأنزيــات ALT و AST في مصـل وكبـد حيوانـات المعاملة بالأكريمايد، وتتفق أيضا مع نتائج دراسة Chinoy الذين أكدوا على Memon,2001; Dheer et. al., 1987)

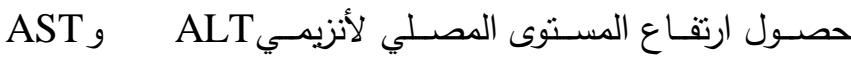

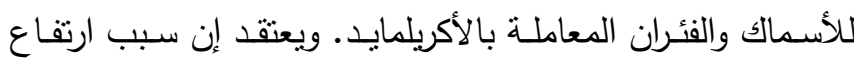

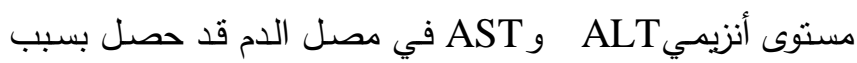

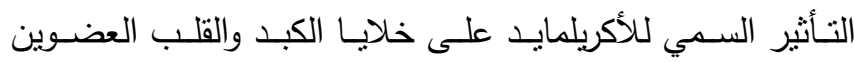

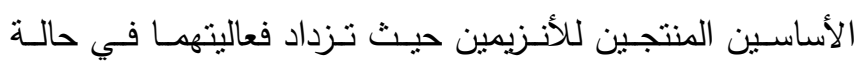
الإصابة بأمراض القلب والتهاب الكبد. كما يعود السبب أيضا إلى لى لئل

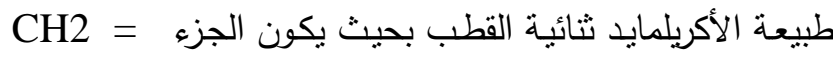

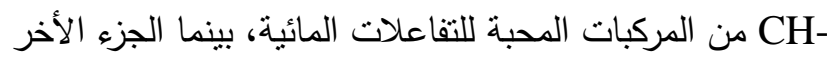

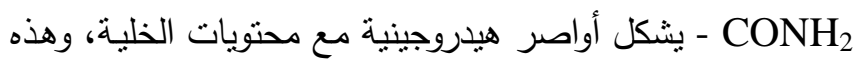
القطبية ربما تعزز قدرة تغيير نركيب غشاء الخلية وتجعل غشاء الخلايا البرنكيمية للكبد أكثر نفاذية.

قد يعود السبب في انخفاض مستوى الأنزيماتALT و ALTT

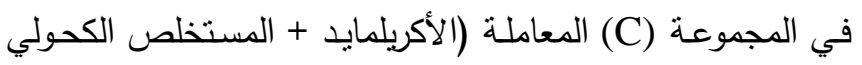

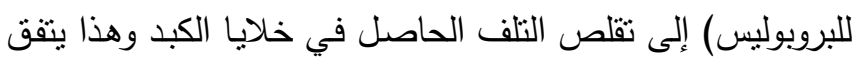

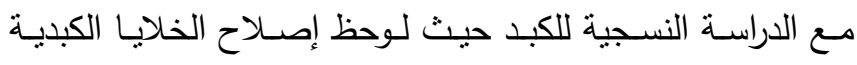

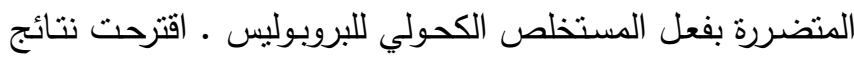

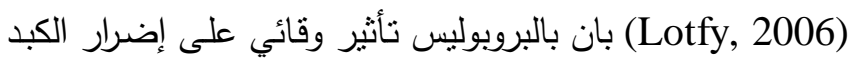

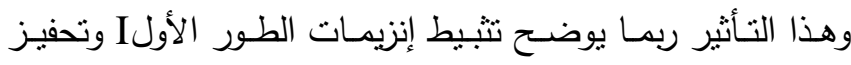
إنزيمات الطور الثاني II ، كذلك أثنارت الدراسات إن البروبوليس يغير في تركيز الأنزيمات الكبد ALT و AST وهذا مـا اكدة الكيات بان للمستخلص البروبوليس نأثيرات وقائية للكبد

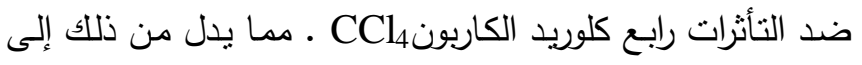

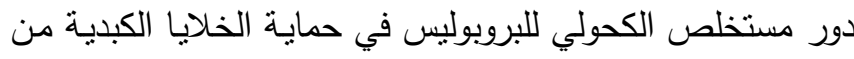

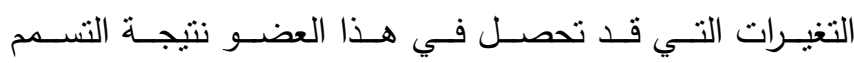
بالأكريلمايد، وارجاع مسنوى نلك الأنزيمات إلى مستواها الطبيعي

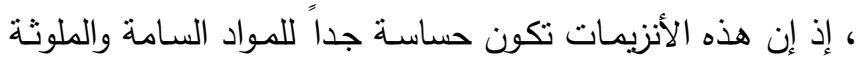
التي تنخل داخل الجسم (Moussa,1997) .
ايجابي في حماية الدهون الفوسفاتية التي تعد الدكون الرئيسي

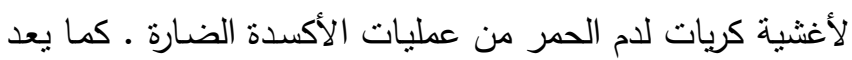

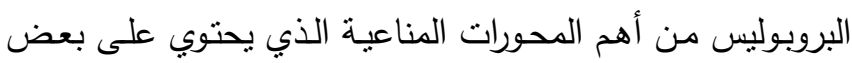

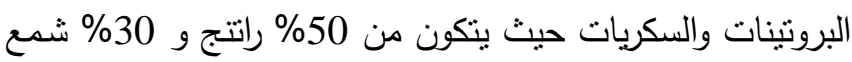

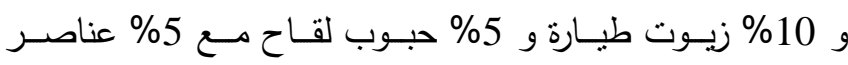
كيمياويـة مثل (Fe, Zn, Ca, Ni, Mg) ذات الأثر المناعي(Castaldo \& Capasso, 2002) . كما يحتوي أيضا

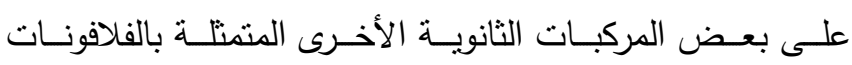

و Quersting Spinobanlcsin منثل Flavonoides Caffic acid و Glalangin الجهاز الدناعي على إنتاج الأضداد (Dimov et. al., 2005).

التغيرات في وظيفة الكبد: أوضــت النتـائج ارتفاعـا معنويـا (P<0.05) في مسـتوى إنزيمات الكبد ALT و AST وفعاليـة إنزيم الفوسفاتيز القاعدي القاني

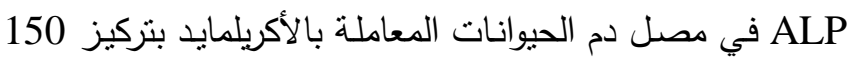

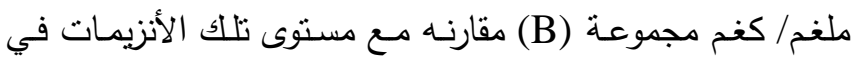

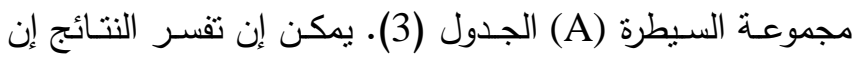

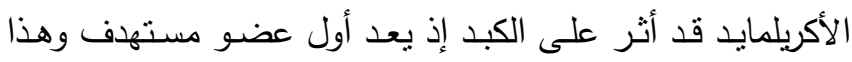

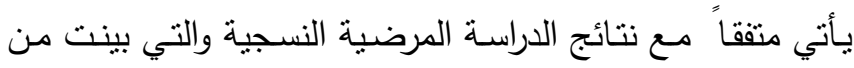

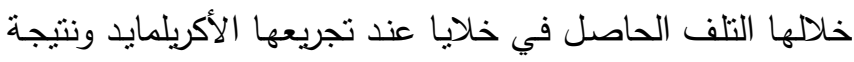

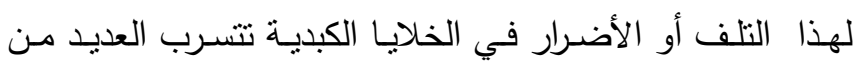
الأنزيمات الموجودة في داخل الخلايا إلى لام (Henry, 2001)

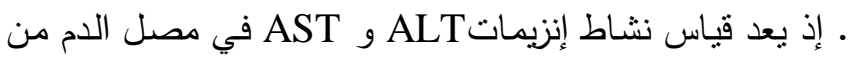

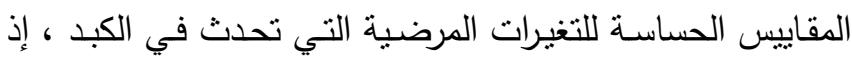

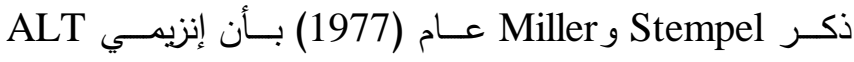

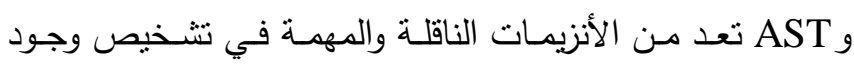

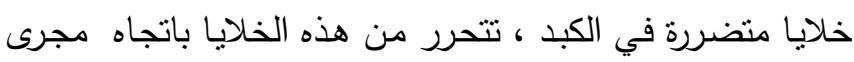

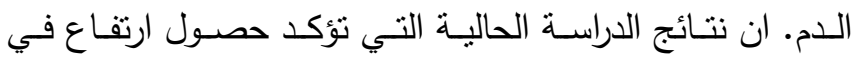

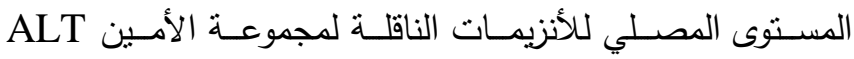

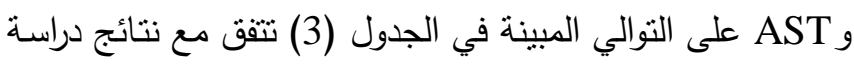

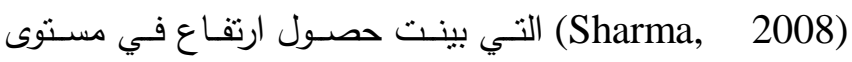


والمعاملـة بالمستخلص الكحولي اللبروبوليس مقارنـة مـع تركيزهمـا

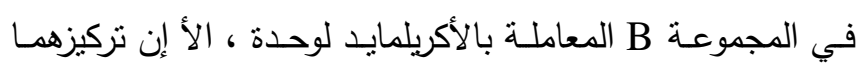
اليوريا والكرياتين لم يصل إلى حد المعنوية (P>0.05) مقارنه ديع

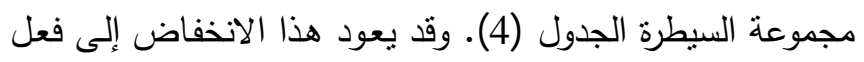
البروبوليس المثبط لتأثنر الاكريلمايد في نركيب كل من الكبيبـة

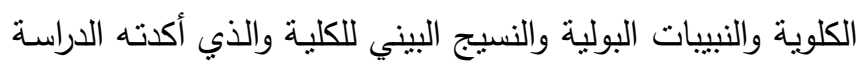
النسجية، أو ربما يكون بسبب تأثير البروبوليس المخفض لليوريا

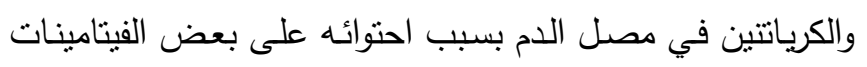
والعناصر المضادة للأكسدة.

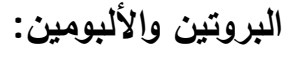

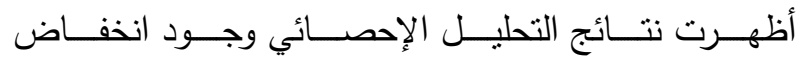
معنوي(P<0.05) في تركيز البروتين والألبومين في المجموعـة

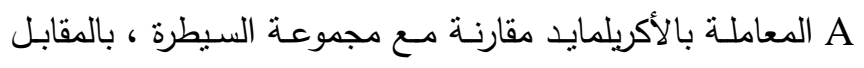

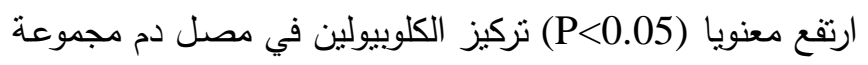

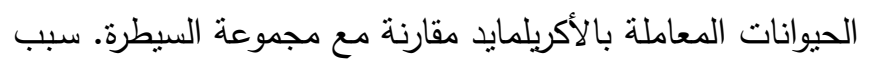

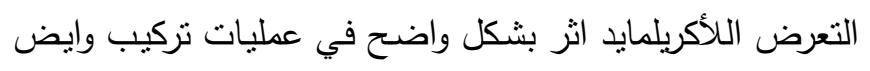

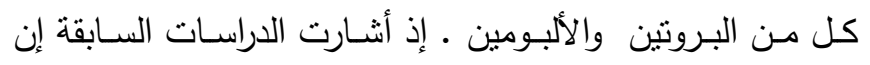
الأكريلمايد يمكن إن يساهم في تقليل تخليق البروتين أو ربما يعود

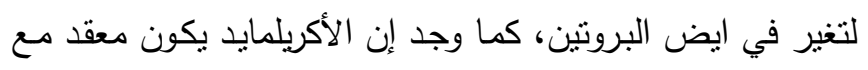
(Husoy وبذلك يعمل على إحداث تشوهات كروموسومية DNA وهكذا أي نركيب غير طبيعي لل et. al.,2005)

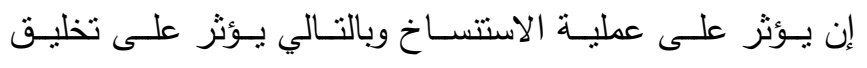
البروتين. كما يمكن إن يعود انخفاض البروتين الكلي والألبومين

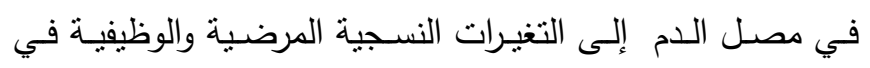
الكبيبات والنبييات الكلويـة، فضـلاً على تأنيره في عملية إعادة امنصاص البروتينات من قبل النبيبات البولية الدانية. إذ إن كمية

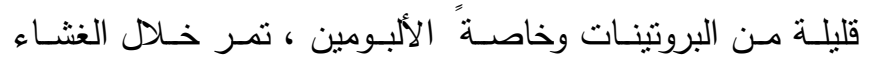
القاعدي الكبيبي في الظروف الطبيعية ـ. وان اغلب ما ينفذ منها

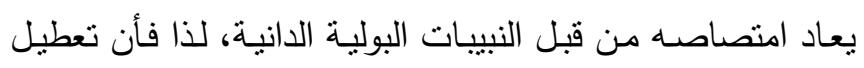

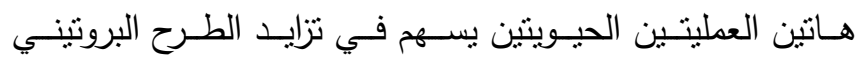
وخصوصنً الألبومين (Anetor,2002).
التغيرات في وظيفة الكلية:

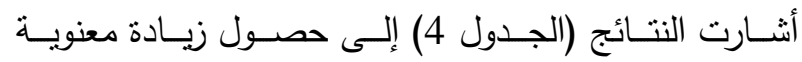
(P<0.05) في تركيز الكرباتين واليوريـا في المجموعـة المعاملـة

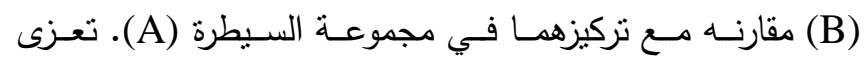

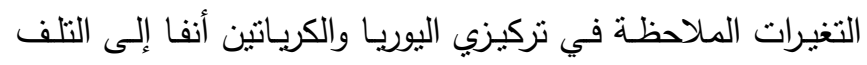
النسيجي الحاصل في الكليـة والذي يؤدي تبعـا لذلك إلى عرقلـة

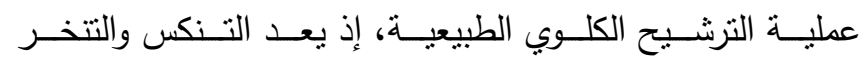

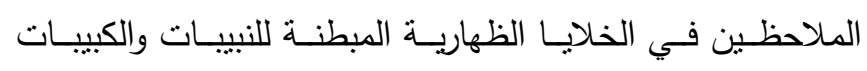
الكلويسة الملاحظـة في الدراسـة النسيجية سبيا مهمـا في فقدان قابليـة هذه النبيبات إعادة امتصـاص وترشيح الجزيئات الكبيرة ،

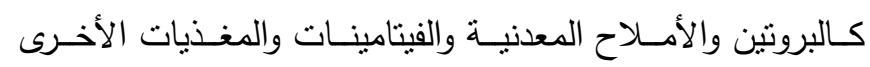

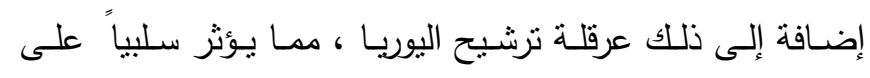

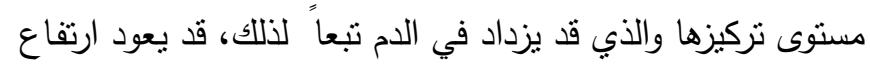

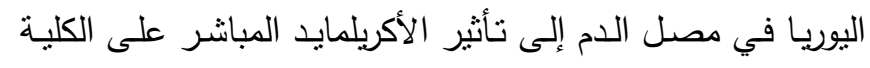

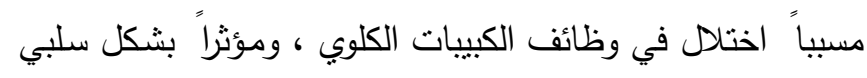

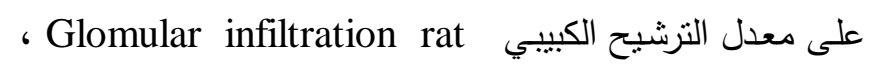
أوقد يعود إلى محاولة الكبد في تقليل سمية الأمونيا الناتجة بفعل التئل

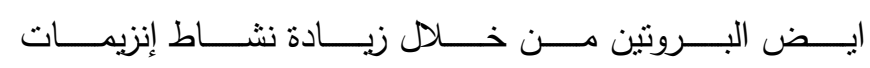
Nucleotide g و Deaminase Dehydrogenase deaminase

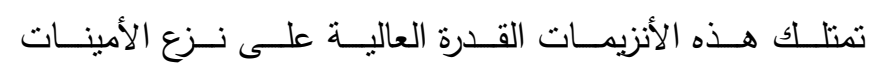

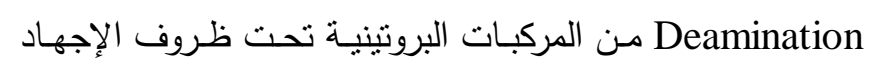

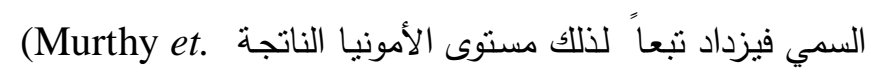

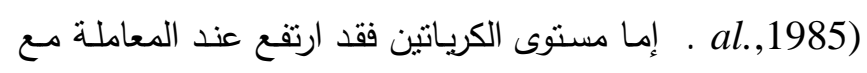

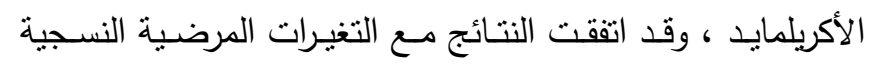

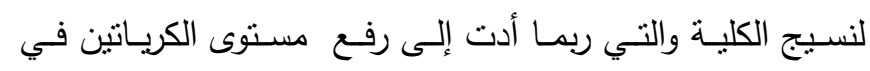

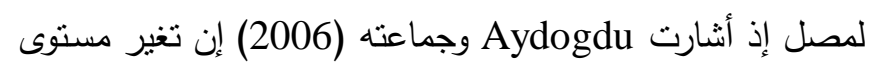
الكرياتين في المصل تتعلق بالتغيرات المرضية النسجية في الكلية (Bioshop et al ., حيث ترتفع نسبة عند الفنثل الكلوي الحادئن .2005) لوحظ انخفاض معنوي(P<0.05) في تركيز كل من اليوريا والكرياتتين في مصل دم مجموعة الحيوانات المعاملة بالأكريلمايد 
الحاصل في عمل الكبد يفسر شـدة التأثير السمي، وان وجود

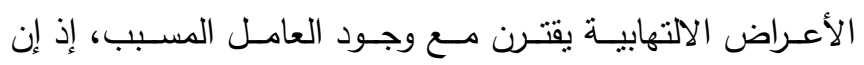

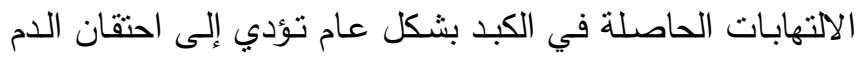

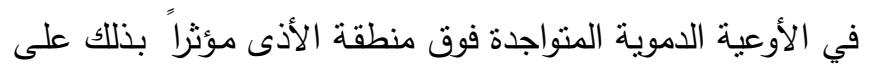

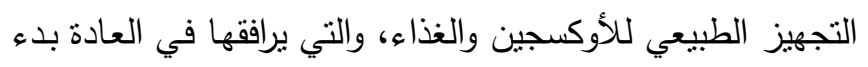

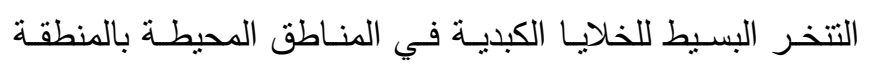

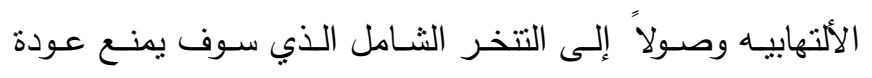
النسيج إلى شكله السوي ، وتدعم نتائج الدراسة الحالية ما ذكرته الإنه (Haziton,1991)

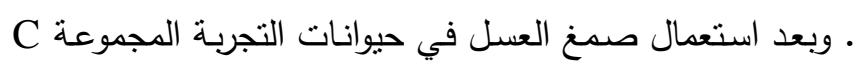

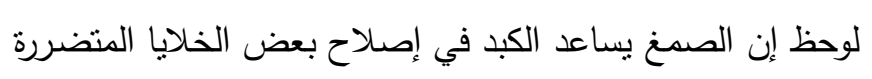

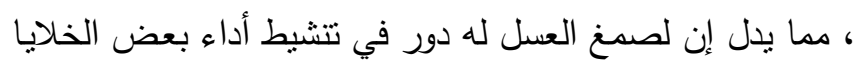
التي أصابها ضرر طفيف من جراء المعاملة بمادة الأكريلمايد.

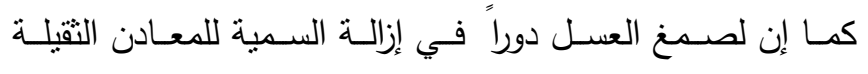
والسموم الصورة (3).

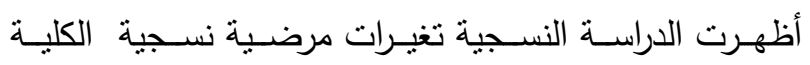

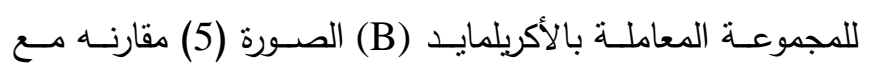

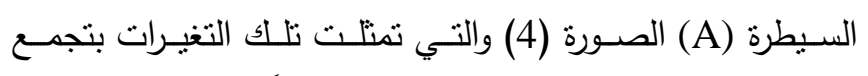

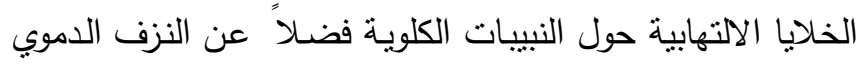

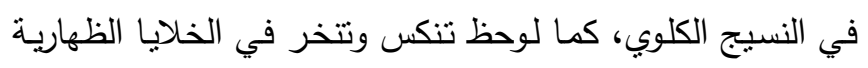

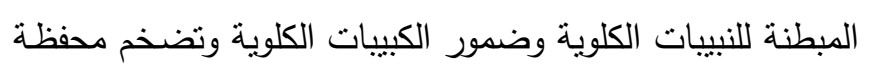
بومان. وقد يعود سبب ذلك إلى فعل الجذور الحرة الدتولدة نتيجة

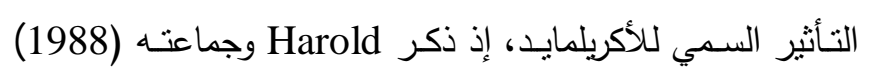
إن الكلية تنـكل العضدو الرئيس في عمليـة طرح السموم خـارج

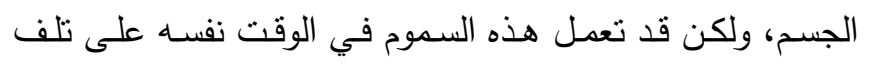

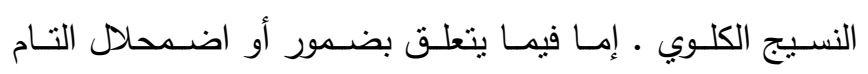

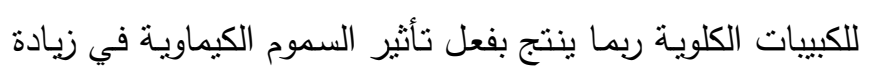

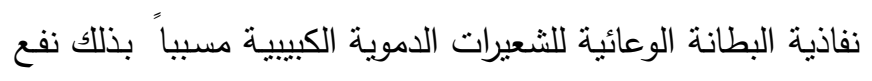

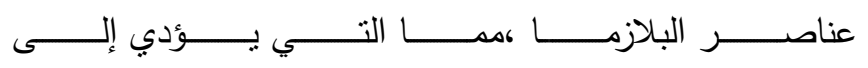

جاءت نتائج ارتفاع تركيز الكلوبيولين في المصل إلى الاستجابة

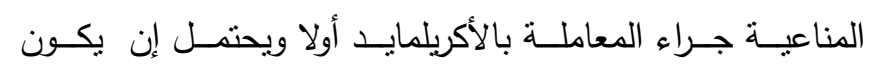

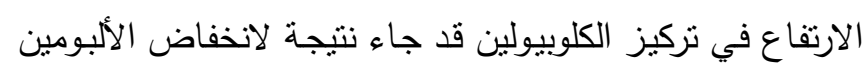

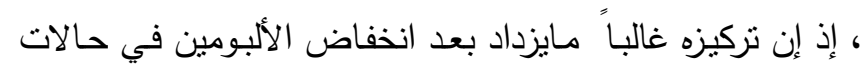

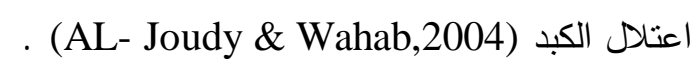
من جانب أخر أنثارت نتائج الجدول (3) إلى إن المستخلص

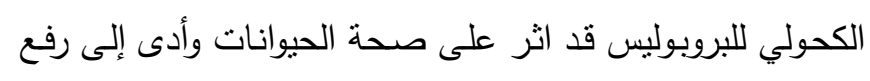

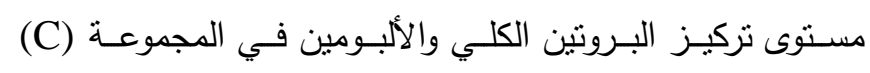

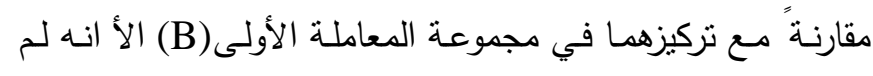

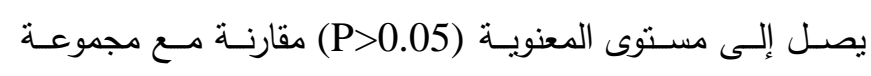

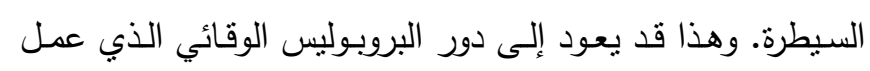

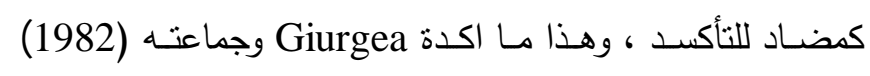

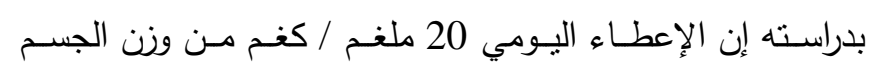

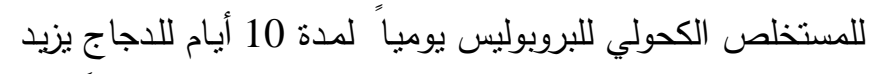

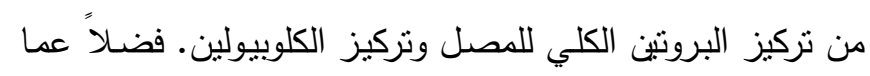

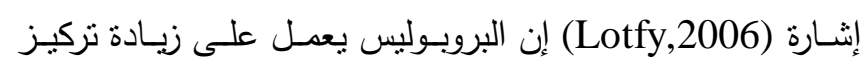

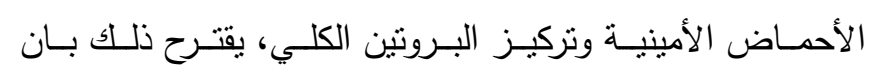

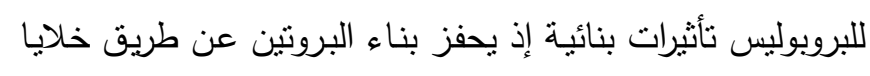
الكبد، وكذلك يحفز الجهاز المناعي للجسم (Lotfy,2006).

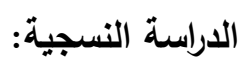

أظهرت الثـرائح النسجية للكبد حصـول تتخر وتنكس في الكي

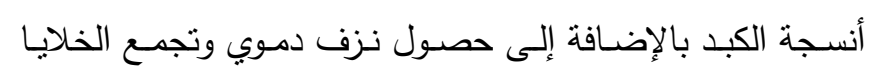

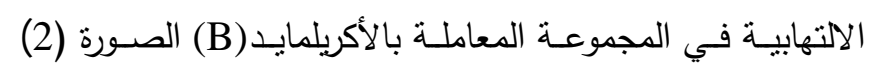

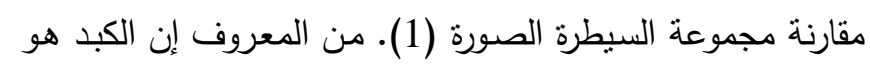

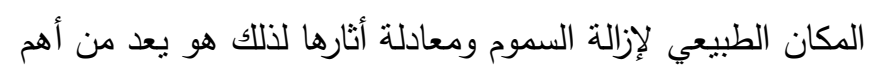

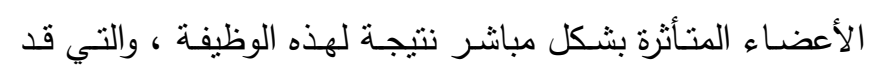

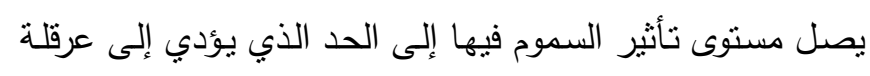

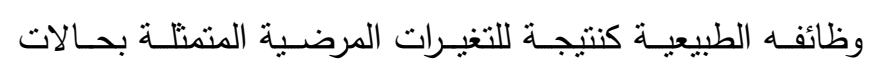

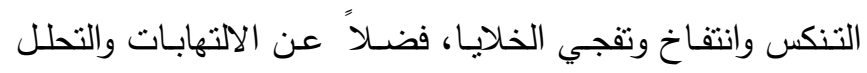

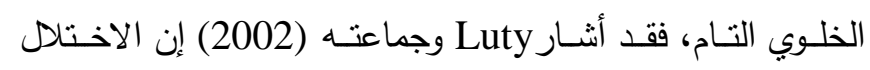


في حيوانـات المجموعـة C الصـورة (6) اذ عمل الصـــغ فـي

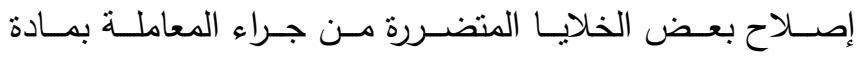

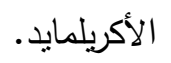

ذوي الكبيبات وانكماشها حيث تحل محل الثُعيرات الدموية مادة باهته الصبغة متجانسة(Luty et. al., 2001) من جانب أخر أظهرت المعاملة بالمستخلص الكحولي البوبوليس ( صمغ العسل ) تحسن ملحوظ في التركيب النسجي لخلايا الكلية

الجدول (1) يبين نأثير الاكريلمايد و المستخلص الكحولي للبروبولس على وزن الجسم ومعدل الكسب الكبان

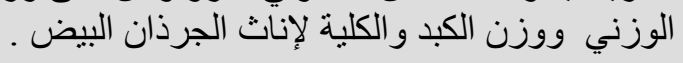

\begin{tabular}{|c|c|c|c|c|c|}
\hline 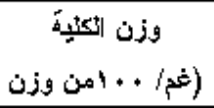 & 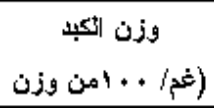 & معلز |نكسب & وزن أبُسمج بعد & 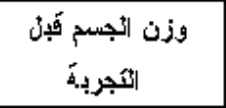 & |أمجاميع \\
\hline$\because \cdot \pm \pm ., \varepsilon>a$ & $\left.1, \eta^{\mu}\right) \pm 0, Y \zeta \quad a$ & $\cdot, \varepsilon\} \pm 1 \eta^{\prime}, \gamma \cdot a$ & - Y' & $Y_{1}^{\mu} \varphi^{\mu} \pm 1 Y \vee, v 1 a$ & A \\
\hline$\cdot, Y^{Y} \pm \cdot, Y Y A b$ & $\cdot, 1) \pm 4, r^{n} \cdot b$ & ., ५० $\pm \circ q_{1} \circ \varphi_{-b}$ & 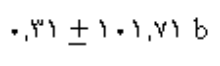 & 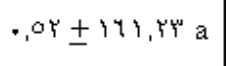 & B \\
\hline$\cdot 11 \pm \cdot, 490 \mathrm{a}$ & $.0 Y \pm 0, A \varepsilon \quad a$ & $\cdot, r^{\mu} Y^{\mu} \pm \varepsilon, Y^{\mu} A-c$ & - YM &.,$Y A \pm 14 Y_{1} .9 a$ & C \\
\hline
\end{tabular}

الأرقام تمنل المعدلات ، بـ الخطأ القياسي.

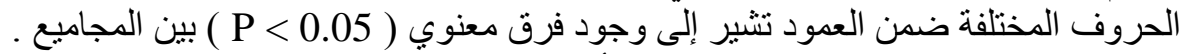

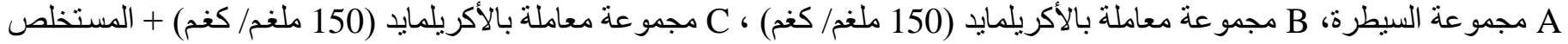
الكحولي للبروبوليس (150 ملغم / كغم).

الجدول (2) ييين تأثير ات الاكريلمايد والمستخلص الكحولي للبروبولس على معايير الدموية لإناث

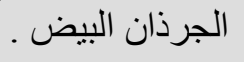

\begin{tabular}{|c|c|c|c|c|}
\hline 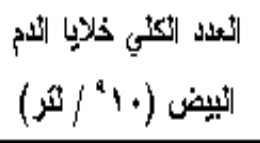 & حبم انذلايا أمرصوص & 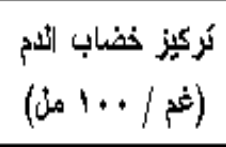 & 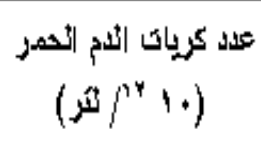 & لمجاميع \\
\hline$\left.\cdot, r^{\mu}\right\rangle \pm 4,1 \cdot b$ & $.01 \pm\left\{.,,^{\prime \prime} \backslash b\right.$ & - & $\cdot, 11 \pm 4, y^{\mu} 4^{n} a$ & A \\
\hline $1, k n \pm\{, y\}$ a & $\cdot,\{\} \pm r q, 1 a$ & $\cdot, 14 \pm 4, y i a$ & $\cdot, 1 v \pm \Psi^{\prime \prime}, 19 b$ & B \\
\hline$\cdot, \varepsilon A \pm 0, q \cdot b$ & 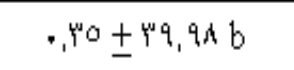 & $\cdot \varepsilon \cdot \pm 1 \varepsilon, 1 b$ & $\cdot, Y 0 \pm 0,9 \varepsilon a$ & $\mathrm{C}$ \\
\hline
\end{tabular}

الأرقام تمثل المعدلات ، بـ الخطأ القياسي.

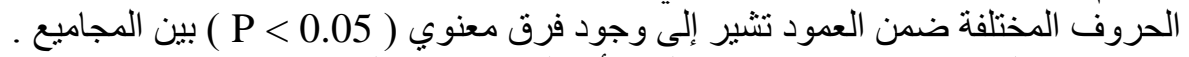

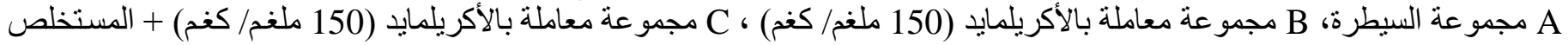
الكحولي للبروبوليس (150 ملغم / كغم). 


$$
\begin{aligned}
& \text { الجدول (3) ييين تأثيثر الاكريلمايد و المستخلص الكحولي للبروبولس على لإنى }
\end{aligned}
$$

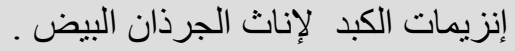

\begin{tabular}{|c|c|c|}
\hline 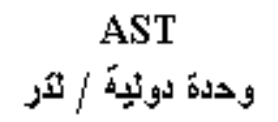 & $\begin{array}{c}\text { ALT } \\
\text { وحلة دو ليّة / ثرَ }\end{array}$ & | أمجاميع \\
\hline$=, r= \pm A \cdot, r=b$ & $\cdot i k \pm \pm$ & A \\
\hline$\cdot, Y 0 \pm 1 Y 0, \cdot 1$ a & $\cdot, 9 \pm 49,1 \cdot a$ & B \\
\hline$\left.\cdot, 10 \pm 9 \varphi^{\mu}, 1\right\}^{\prime \prime} b$ & $, i \vee+\varepsilon \varepsilon_{1}, 9 \mathrm{~b}$ & $\mathrm{C}$ \\
\hline
\end{tabular}

الأرقام تمثل المعدلات ، + الخطأ القياسي.

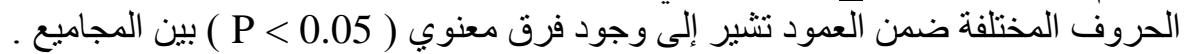

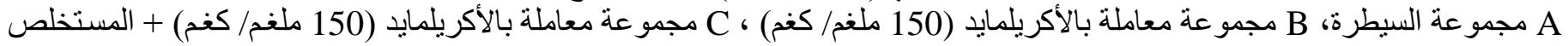
الكحولي للبروبوليس (150 ملغم / كغم).

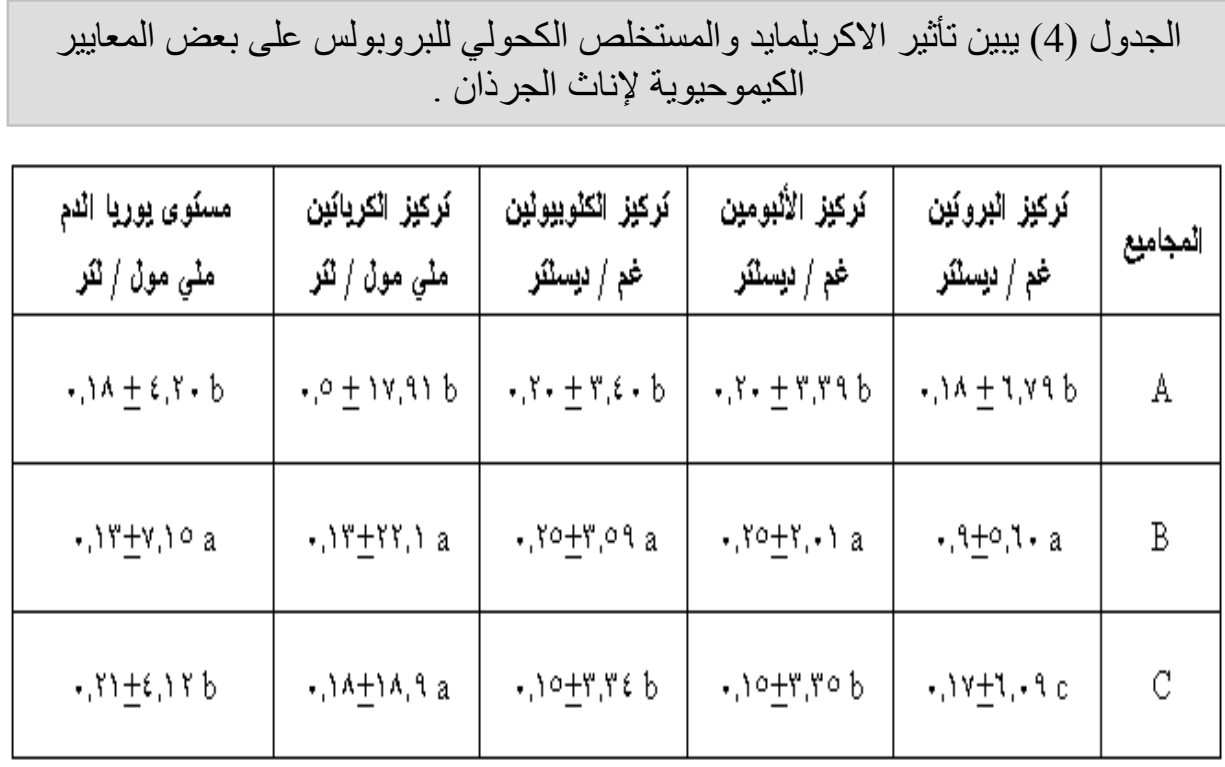

الأرقام تمثل المعدلات ، + الخطأ القياسي.

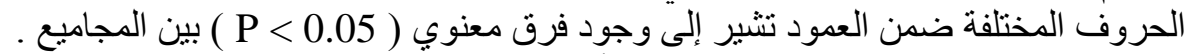

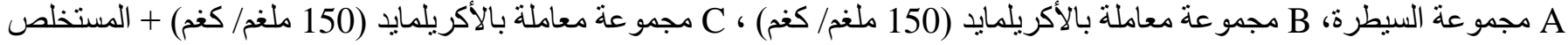
الكحولي للبروبوليس (150 ملغم / كغم). 


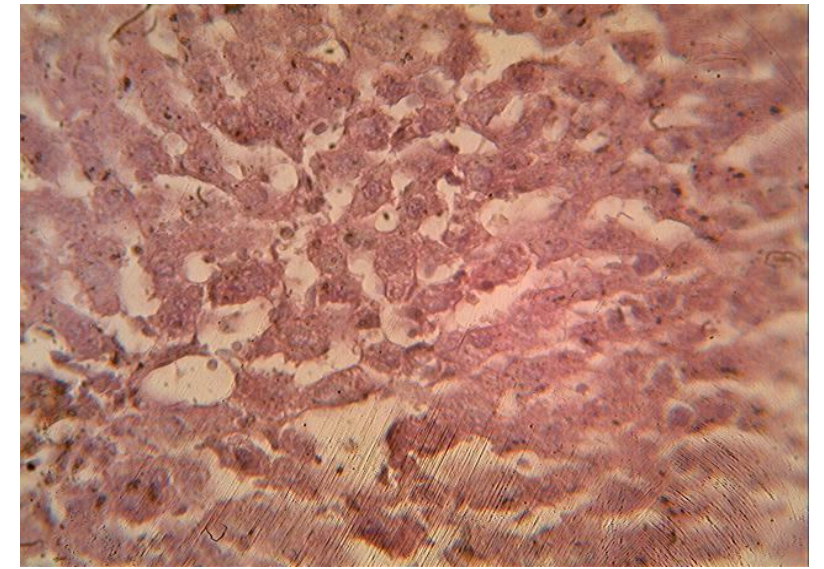

$$
\text { صورة (2) مقطع عرضي في نسيج الكبد لجرذ من }
$$

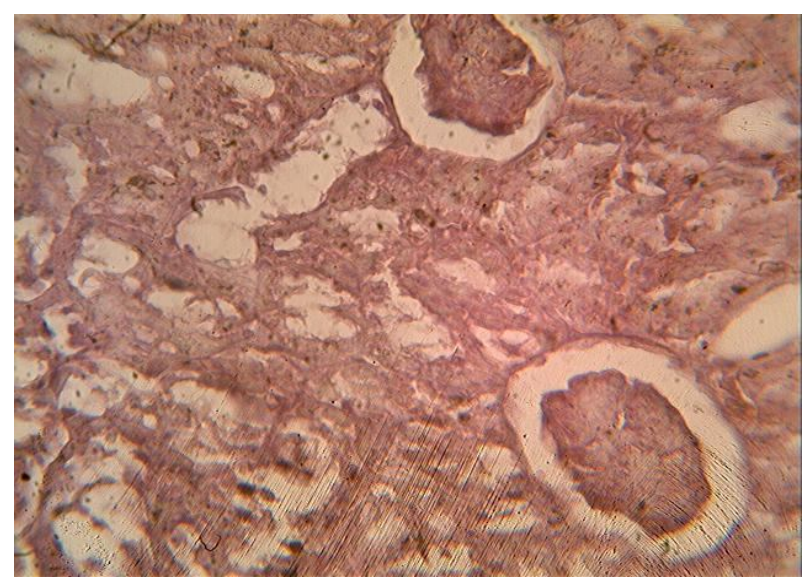

$$
\text { صورة (4) مقطع عرضي في نسيج الكلية لجرذ من }
$$

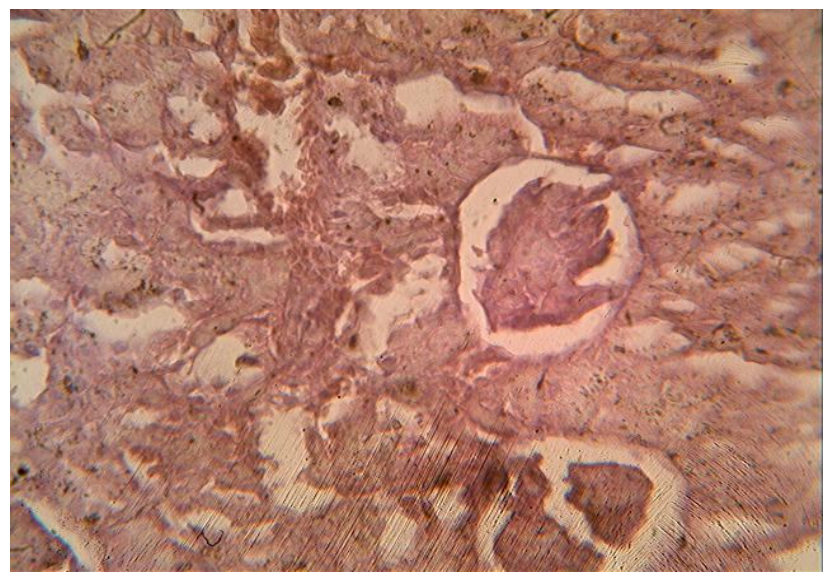

$$
\text { صورة (6) مقطع عرضي في نسيج الكلية لجرذ من }
$$$$
\text { مجمو عة (C) }
$$

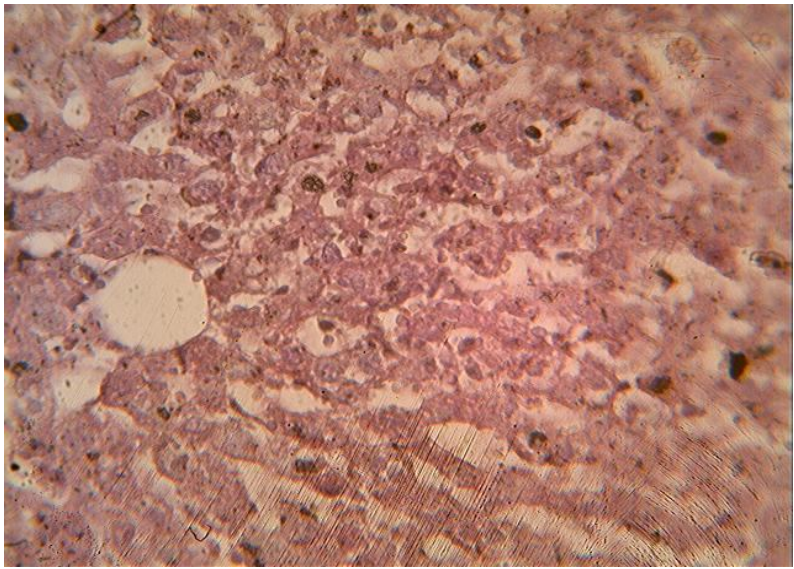

$$
\text { صورة (1) مقطع عرضي في نسيج الكبد لجرذ من }
$$

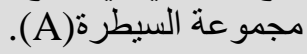

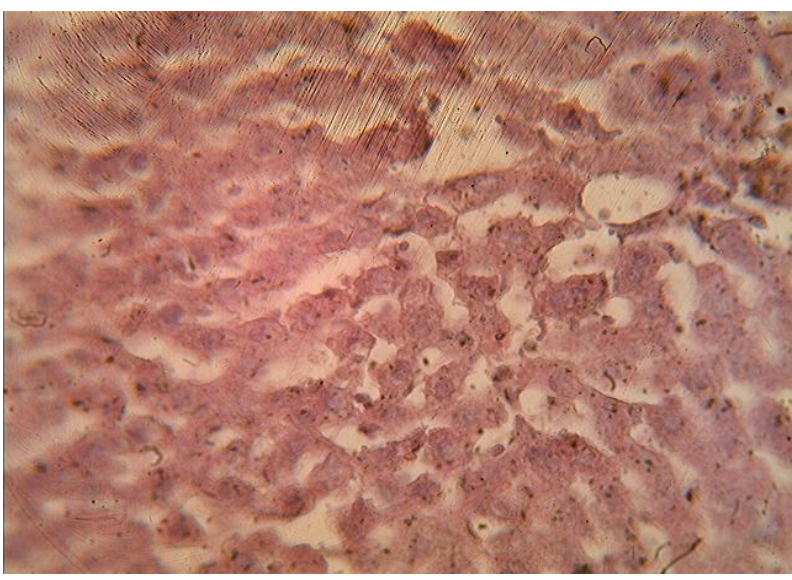

$$
\begin{aligned}
& \text { صورة (3) مقطع عرضي في نسيج الكبد لجرذ من } \\
& \text { مجمو عة (C) }
\end{aligned}
$$

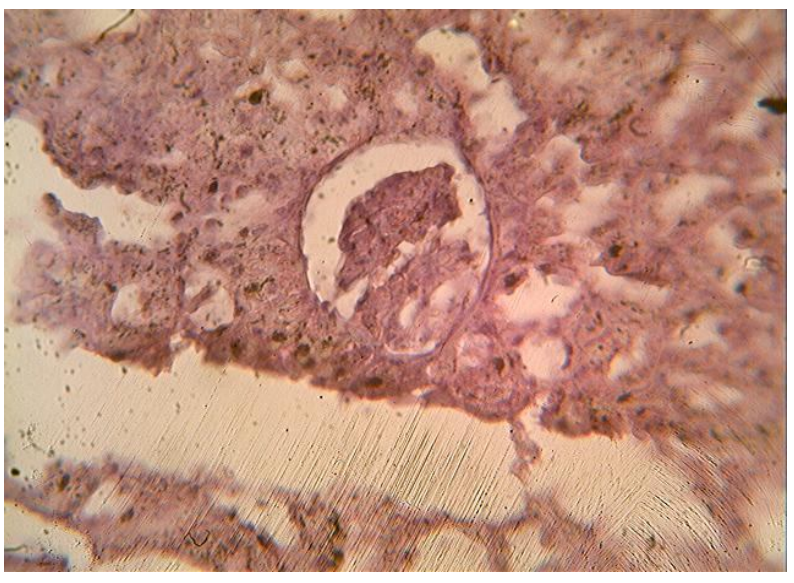

صورة (5) مقطع عرضي في نسيج الكلية لجرذ من مجموعة (B) مرض في 
- Brunton, N. ; Grimly, R. and Murray, B. (2005). Status report on acrylamide in potato products, Teagass, The National Food Center, Dublin

- Castaldo, S. and Capasso, F. (2002). Propolis, an old remedy used in modern medical. Fitoerapia. 73 (1): $1-6$.

- Chanarin, I.(1989). Laboratory haematology. An Account of laboratory Techniques. Churchill Livingstone, Hong Kong.

- Chinoy, N. J. and Memon, M. R. (2001). Beneficial effects of some vitamins and calcium on fluoride and aluminum toxicity of gastrocnemius muscle and liver of male mice, Fluoride, 34, 21-33.

- Coles , E. H.(1980) Veterinary clinical pathology $3^{\text {rd }}$ ed. W.B. Saunders co. Philadelphia . PP. : 190192.

- Dheer, J. M. ; Dheer, T. R. and Mahajan, C. L. (1987). Hematological and haematopitic response to acid stress in an air breathing fresh water fish Channa punctatus Bloch, J. Fish Bio. ,30, 577-588.

- Dimov, V.; Bankova, V. and Popov, S. (2005). Immunodulatory action of propolis : Prophylactic activity against G-infectious and adjuvant effect of the water soluble derivative. Bulgarian Academy of sciences. V. 10 (12).P:817-823.

- Dixon, R. L. (1985). Aspect of male reproductive toxicology in hemminks, ksoman - vainino , $\mathrm{H}$ (eds) occupational hazard and reprodurion, Hemisphere, public cro, Washington, Neo York. London.

- European Commission (EC) (2000), Risk Assessment of Acrylamide. Draft risk assessment report prepared by the UK on behalf of the European Union in the framework of council regulation (EEC) 793/93 on the evolution and control of the risks of existing substances.

- Ghanayem, B. I. ; Witt, K. L. ; EI- Hadri, L. ; Hoffler, U. ; Kissling, G. E. and Shelby, M. D. (2005). (Comparision of germ cell mutagenicity in male CYP2E1 - null and wild type mice treated with acrylamide: Evidence supporting a glycidamide-mediated effect, Biol . reprod ., 72, 157- 163.

- Giurgea, R. Poprescu, H. Polinicencu, C, Coprean, D. and Moje, D.(1982). Effect of standardized propolis extract on the central lymphatic system

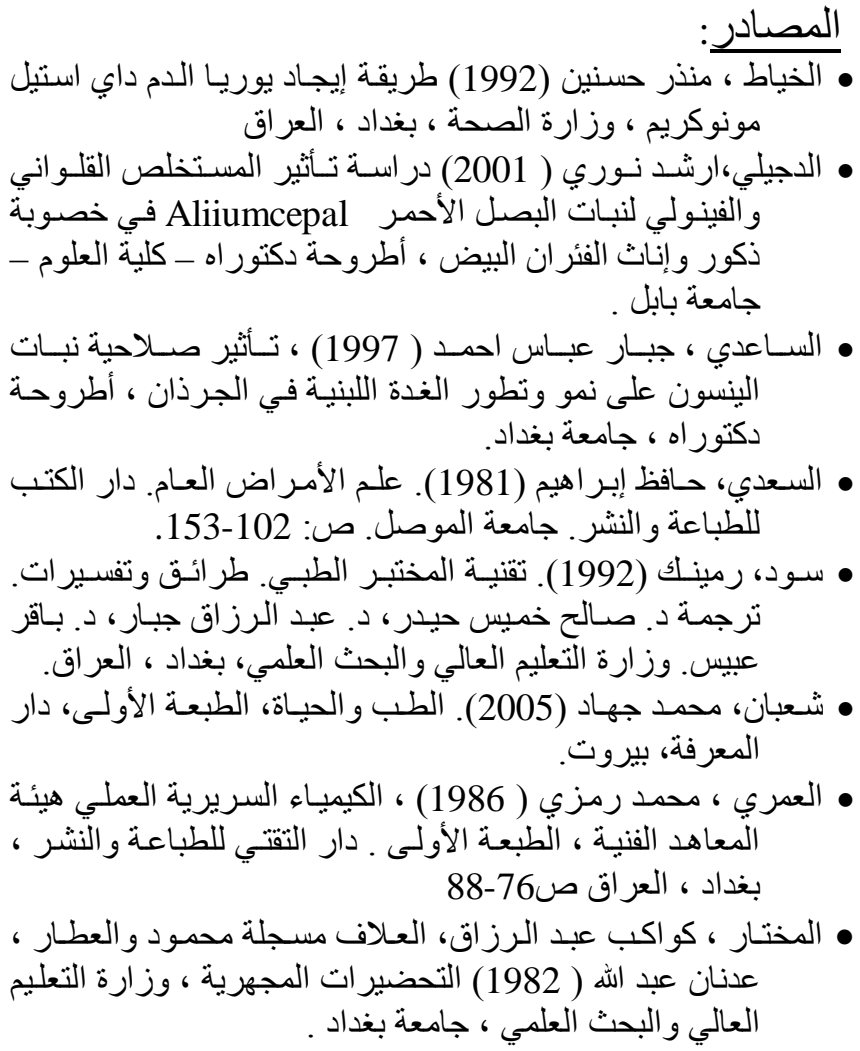

- AL-Joudy, F. S. and Wahwb, N. A. (2004). The utilization of an index for serum globulin compensation in disease associated with decrease serum albumin . Med. J. Malaysia, 59 (4): 495-501.

- Amoros, M.; Sauvager, F.; Girre, L. and Cormier, M. (1992). In vitro antiviral activity of propolis . Apidologie. 23, 231-240.

- Anetor, J.I. (2002). Serum uric acid and standardized urinary protein: Reliable bioindicators of lead nephropathy in Nigerian lead workers. African. J. Biomed. Res., 5: 19-24.

- Aydogdu , N. ; Atmaca, G. ; Yalcin , O. ; Taskiran , R. ; Tastekin , E. and Kaymak , K. (2006). Protective effects of 1- carnitine on myoglobinuric acute renal failure in rats. Clin. Exp. Pharmacol. Physiol. 33 (1-2) : 119-124.

- Barber, I. J. (2001). Overview of acrylemide toxicity and metabolism. Workshop on Acrylemide in food toxicology and metabolic consequences working group. North America. P:1-4.

- Boishop , M. L. ; Fody , E. P. and Schoeff , L. ( 2005 ). Clinical chemistry . 5 th (ed.). Lippincott Williams and Wilkins : 223-226. 
dermally absorbed C14DDT in the organs of waster rats. Ann. Agric. Environ. Med. 9: 215223.

- Moussa, F. (1997). Acute toxicity of zinc and lead to the Egyptian toad Bufo regularis Biochemical and physiology observation. Environ- Res. Vol. 22 (A). 343-363.

- Murthy, B. N.; Sreenivaslu, R. M. and Ramana, K. V. (1985). Significance of AMP- deaminase, Adnosine deaminase and Xanthine dehydrogenase in the tissue of fresh water fish Tilapia mosambica exposed to Lindane. Environ. Ecol., 3: 320- 323.

- Pelucchi, C. ; Galeone, C. Levi, F. ; Negri, E. ; Franceschi, S.; Talmini, R. ; Bosetti, C. ; Giasoca, A. and La Vecchia , C. (2005). Dietary acrylamide and human cancer, Int. J. cancer, $118,467-471$.

- Reitman , S. and Frankel, S. ( 1957) A Colorimetric method for the determination of serum glutamic oxaloacetic and glutamicpyruvic transaminas AM.J. Clin , path , : 28:56-63

- Rodkey , F. L. ( 1965). Directed spectrophotometer determination of albumin in human serum . Clin. Chem. , 1, 478.

- Schefler , W.C.(1980) Statistics for biological science $2^{\text {nd }}$ ed. Addison Wesley, pub. Co. London. Amsterdam, : PP. 121.

- Sharma, A.; Sharma, R. and Jain,, J. (2008). Biochemical changes in the liver of Swiss albino mice orally exposed to acrylamide. $\mathrm{Mj}$. Int. $\mathrm{J}$. Sci. Tech. , 2 (3), 542- 550.

- Sood , R. ( 1996) Hematology for students and practitioners $4^{\text {th }}$, ed. Japee brothers medical publishers (P) LTD. Indian . PP325-318.

- Stempel, D. A. and Miller, J. J. (1977). Lymphopenia and hepatic toxicity with ibuprofen. Toxicol., 90: 657-658.

- Sumner, I. F. (2001). Overiew of Acrylemide toxicity and metabolism. Kellogg Company .kraft food , NA, 26, P:4-12.

- Tareke, E. ; Rydberg, P .; Karlsson, P. ; Eriksson, S. and Tomqvist, M. (2002). Analysis of acrylamide. A carcinogen formed in heated foodstuffs, J . Agric . Food Chem., 50 , 49985006.

- Tietz , N.W. (1982) . Fundamentals of clinical chemistry , $2^{\text {nd }}$ edition, W.B. Saunders company , Philadelphia , pp. 70.271,294,335,337,510 and the immunological reactions of chickens. Clujul Medical, 55, 6-72.

- Gold , B. G. ; Voda, J. ; Yu, X. and Gordon, H. (2004). The immunosuppressant FK 506 elicits a neuronal heat shock response and protects against acrylamide neuropathy, Exp. Neurol., 187, 160-170.

- Greenway, W.; May, J.; Scaysbrook, T. and Whatley, F. R. (1991). Identification by gas chromatography - mass spectrometry of 150 compounds in propolis. Zeitschrift fur nature forschung. $46: 111-121$.

- Harold, G.; Reddy, P. M. and Ramamurthi, R.(1988). Changes in the protein metabolism in live and kidney of Mus boodugs gray after oral BHC feeding. Bull. Environ . Contam. Toxicol., 41: 822-827.

- Haziton , W. ( 1991). Acrylemide and body weight . Fundam Appl Toxicol. A service of the National institutes of Health , I , (Z) P: 315-316.

- Henry, J. B. (2001). Clinical diagnosis and management laboratory methods. 20th (ed.). W.B. Saunders Company : 268-269.

- Husoy, T. ; Abramsson- Zetterberg, L. ; Olstorn, H. B. ; Paulsen, J. E. and Alexander, J. (2005). Adenomatous polyphonic coli influence micronuclei induction by PhiP and acrylamide in mouse erythrocytes, Mutat. Res., 580, 111-118.

- Known, Y; park, D; Shine; E; Jung, B. (2004). Antioxidant propolis attenuates kainite induced neurotoxicity via adenosine $\mathrm{A}(1)$ receptor modulation in rat. Neurosci lett. 355 : 231-235

- Krell , R. ( 1996) . Value - Added products from beekeeping . Agricultural services bulletin. No. 124.

- Lin, S. ; Chung, C.; Hiang, C. and Hus, S. (1999). The influence of propolis ethanol extract on liver microsomal enzymes and Glutathione after chronic alcohol administration. American Journal of Chinese Medicine XXVII (1): 93-83.

- Lotfy, M. (2006). Biological activity of bee propolis in health and disease. Asian pacific, J. Cancer Prevention, (7):22-31.

- Luty, S.; Przebirowska, D. O. Latuszynska, J. and Rodak, M. T. (2001). Histological and ultrastractural studies of rats exposed to carbaryl. Ann. Agric. Environ. Med., 8:137-144.

- Luty, S.; Tokarska- Rodek, M.; Latuszynska, J. And Przebirowska, D. (2002).Distribution of 
- U.S. Environmental protection Agency , USEPA ( 1990) . Acrylemide causes preimplantation Abnormalities in Embryo and induces chromatin adducts in male germ cells of mice . Intergraded Risk information system ( IRIS) 29P. :177-178.

- Weir, D. M.(1989). Hand book of experimental immunology. 2: Black well scientific publications: $321-329$.

- Xiwen, H. and Jing, L.I.(1992), studies on biochemical mechanism of neurotoxicity induced by acrylemide in rats. Biomed Environ sci. , ( 5) P: 276-281.
- Tyalor , J.S. ( 2002) . A look at the energizing properties of the royal jelly, bee pollen, propolis and honey health media publishing London .

- Tyl, R. W. ; Marr, M. C. ; Myers, C. B. ; Ross, W. P. and Friedman, M. A. (2000). Relationship between acrylamide reproductive and neurotoxicity in male, Reprod. Toxicol, 14, 147157.

- U.S. Environmental protection Agency, USEPA ( 1999).Integrated risk information system (IRIR). National center for environmental assessment office of research and development. P:67.

\title{
AStudy of the effect of propolis extract (Bee glue) in reducing toxicity of Acrylamide in female rats.
}

\author{
Hussein K.A. AL-Maeeali *
}

Wisam A.W. AL-Khalidi *

Jameela khadom abdulhsn

${ }^{*}$ College of Education

University of Al-Qadisiya

College of veterinary

\section{Abstract:}

The present study was designed to determine the toxic effects of Acrylamide on Liver and Kidney organs functions and parameters blood in female rat, as well as, the evaluation of the benefit role of Propolis in relieving these effects in female rat. The results revealed that in studied, which were as follows:

Significant decrease $(\mathrm{P}<0.05)$ in body weight, body weight gain compared control group.Significant increase $(\mathrm{P}<0.05)$ in Liver weight and Significant decrease $(\mathrm{P}<0.05)$ in kidneys weight compared control group. Significant decrease $(\mathrm{P}<0.05)$ in $\mathrm{RBCs}$ count, $\mathrm{Hb}$ estimation and $\mathrm{PCV}$, WBCs compared control group. Significant decrease $(\mathrm{P}<0.05)$ in total protein and albumin compared control group, and significant increase $(\mathrm{P}<0.05)$ in total globulin, Creatin and Urea compared control group. Significant increase $(\mathrm{P}<0.05)$ in ALT, AST enzymes compared control group. The histopathological results revealed a blood vessel congestion and tissue hemorrhage, in each of liver, kidneys, as well as, while the tubular epithelial cells suffered from necrosis. The hepatocytes showed a necrotic and degenerative, and an increase in the number of kupffer cells. On the other hand, the results revealed that supplementation of porpolis with provender will relieve the toxicological effects of acrylamide, in all parameters included in this study. It can be concluded that the exposure to porpolis present led to an toxicological changes, while Acrylamide supplementation relieve these effects, as well as its role in retention of Acrylamide. 